\title{
Genetic Analysis for Mapping of Physiological Traits Related to Seed Vigour in Rice Through Association Mapping
}

\author{
Priyadarshini Sanghamitra \\ NRRI, Cuttack \\ Deepak Kumar nayak \\ Cuttack Homoeopathic Medical College \\ saumya ranjan Barik \\ NRRI, Cuttack \\ Elssa Pandit \\ FM University, Balasore \\ Ramakrushna Bastia \\ NRRI, Cuttack \\ Shakti Prakash Mohanty \\ NRRI, Cuttack \\ Jyotirmayee Mishra \\ ICAR-NRRI, Cuttack \\ Abhisarika Behera \\ NRRI, Cuttack \\ Auromeera Sahoo \\ NRRI, Cuttack \\ Suchismita Patttanaik \\ NRRI, Cuttack \\ Arpita Moharana \\ NRRI, Cuttack \\ Debabrata samal \\ NRRI, Cuttack \\ Sharat Kumar Pradhan ( $\nabla$ pradhancri@gmail.com) \\ Central Rice Research Institute,Cuttack https://orcid.org/0000-0001-7716-0721
}

\section{Original article}

Keywords: Seed vigour, molecular markers, association mapping, physiological traits, indica rice namely rate of imbibition (RI), germination \% (GP), germination index $(\mathrm{GI})$, root length (RL), germination rate (GR), seed vigour index-1 (SVI-1), rate of plumule elongation (RPE), shoot length (SL), seedling dry weight (SDW), rate of shoot growth (RSG), SVI-II and absolute growth rate (AGR)

Posted Date: March 16th, 2021

DOl: https://doi.org/10.21203/rs.3.rs-288996/v1

License: @ (i) This work is licensed under a Creative Commons Attribution 4.0 International License. Read Full License 


\section{Abstract}

\section{Background:}

Good quality seed is an important factor for a good crop. Vigor is the key performing trait of quality seed. Genomic regions controlling the physiological traits related to seed vigour are not fully reported.

Results: A panel was prepared by including genotypes from all the groups of the fifteen physiological traits representing a population of 250 germplasm lines. Wide variations were observed for the 15 physiological traits in the population. The population was classified into 6 genetic groups. Presence of linkage disequilibrium (LD) was detected in the panel population based on the fixation indices of the subpopulations. Moderate values of gene diversity, polymorphic information content (PIC) and other diversity parameters were estimated from the population by genotyping with 109 SSR markers. The population was classified into subpopulations and sub-clusters showed relation with the genotypes for their physiological traits. Ten physiological traits were detected to be significantly associated with SSR markers analyzed by both the General linear model (GLM) and Mixed linear model (MLM). A total of 19 novel QTLs controlling different physiological traits namely $q G P 6.2$ and $q G P$ 8.2 for germination \% (GP); qGR 9.1 for germination rate (GR); qGI 1.2, qGI 6.1, qGI 8.1, qGI 11.1 and $q G I 12.1$ for germination index (GI); qRPE1.1 and $q R P E 8.1$ for rate of plumule elongation (RPE); $q A G R 8.1$ for AGR; $q R S G 1.2$ and $q R S G 12.2$ for rate of shoot growth (RSG); qRGR3.1 and qRGR11.1 for relative growth rate (RGR); qSVI 1.1 for seed vigour index I (SVI I); qSVII 1.1, qSVII3.1, and qSVII12.1 for seed vigour index II (SVI II), and $q R R G 8.1$ for relative root growth rate were identified. The reported QTL for root length, $q R L 11.1$ was validated in this mapping population. Additionally, QTLs, qRPE8.1 and $q A G R 8.1$ of traits, RPE and AGR; $q G / 6.1$ and $q G P 6.2$ of GI and GP; $q G / 11.1$ and $q R L 11.1$ of GI and RL; $q A G R 8.1$ and $q R R G 8.1$ of AGR and RRG, and $q R S G 3.1$ and $q R G R 3$. 1of traits RSG and RGR were detected for co-localization or co-inheritance.

Conclusion: The traits identified and markers detected in the association analysis will be useful for improvement of seed vigour trait through marker-assisted selection in rice.

\section{Background}

The genetic potential of a plant variety is fully manifested by use of quality seed which is considered as the basic and most vital input for crop production. A good quality seed not only ensures high yield but also considered as a mega factor for enhancing crop productivity (Chauhan et al. 2015). Simultaneous increase in population and adverse effects of climate change to rice crop becoming a threat to meet the world food demand which is expected to reach almost double by 2050 (Hunter et al. 2017; Pradhan et al. 2019a). Rice is a life saving grain to feed for more than half of the world population and necessitates increasing the productivity of the crop (Fukagawa and Ziska, 2019). Seed vigour is one of the most important determinant of seed quality, directly influences the crop productivity by delivering the genetic and yield potentials of the seed while ensuring uniformity in seed germination, seedling growth, establishment of seedling in the field and withstanding unfavourable environmental condition (Rajjou et al. 2012; Ventura et al. 2012). In addition, high seed vigour is also equally important for direct seeding as it enhances early crop establishment (Yamauchi and Winn 1996; Mahender et al. 2015) and produces vigorous seedling that can compete with weeds (Dingkuhn et al. 1999; Rao et al. 2007). Improving the seed vigour of rice remains a breeding challenge in crop research (Finch-Savage and Bassel, 2016) as it is not only essential to enhance the yield but also can improve crop resilience against adverse effects of climate change and biotic impediments to crop yields (Daniel, 2017).

Seed vigour via physiological growth parameters is a complex trait controlled by many quantitative trait loci (QTLs). Quantitative inheritance of this trait has made it difficult to identify the contribution of genetic factor by conventional genetic analysis. To investigate the inheritance of such complex trait, the QTL analysis has successfully proven as a powerful tool in the last decades. The detected QTLs for rice seed vigour were associated with many physiological traits viz., root length, shoot length, dry weight of seedling, germination rate, radicle length, root activity, coleoptile length, mesocotyl length, germination potential, germination index and time for 50 \% germination (Regan et al. 1992; Redona and Mackill, 1996; Cui et al. 2002; Miura et al. 2002; Zhang et al. 2005; Fujino et al. 2008; Wang et al. 2010; Dang et al. 2014; Xie et al. 2014; Liu et al. 2014; Zhang et al. 2017; To et al. 2019; Zhao et al. 2019).

QTLs governing radicle length and mesocotyl length were mapped which contributed significantly for phenotypic variance (PV) of these traits (Xie et al. 2014; Lee et al. 2012). Control of root length were located on chromosomes 1, 2, 3, 5, 6, 7, 8, 10 and 12, exhibiting 3.9 to 27.1 \% PV (Redona and Mackill, 1996 ; Cui et al. 2002; Zhang et al. 2005; Dang et al. 2014; Zhang et al. 2017). QTLs controlling shoot length were identified using various mapping populations which exhibited PV of 1.1 to 58.8 \% (Redona and Mackill, 1996; Huang et al. 2004; Zhang et al. 2005; Abe et al. 2012; Dang et al. 2014; Zhang et al. 2017). QTLs for root dry weight were located on chromosome 1, 5 and 10 and ranged the PV from 2.9 to $24.1 \%$ (Cui et al. 2002). Shoot dry weight (SDW) was reported to be controlled by QTLs and located on chromosome 1, 3, 5, 6, 9 and 12 (Cui et al. 2002 and Dang et al. 2014). In addition, QTLs for total seedling dry weight were identified in the regions of chromosome 1, 2, 3, 4, 5, 6, 8, 9,10 and 12 from different mapping populations contributing PV of 1.2-17.4\% (Cui et al. 2002; Zhang et al. 2005; Zhang et al. 2017). QTLs mapping for germination rate were reported on chromosomes 1, 2, 3, 4, 5, 6, 7, 8, 10, 11 and 12 by earlier researchers in rice (Cui et al. 2002; Zhang et al. 2005; Wang et al. 2010; Wang et al. 2010; Liu et al. 2014).

Genetic analyses for seed vigour in rice were based on bi-parental segregating population mostly while very few analysis were through association mapping. Linkage disequilibrium (LD) based association mapping is a very successful approach of gene mapping. Using this mapping approach, QTL identification is possible with a higher resolution and multiple complex loci simultaneously by exploiting the available natural variation (Anandan et al. 2016; Pradhan et al. 2016; Pandit et al. 2017). Genome mapping with SSR markers are widely employed to assess genetic diversity and genetic structure in rice and several other crops as they are hyper variable, co-dominant, robust, multi-allelic in nature, chromosome specific and greatly facilitated linkage map construction (Barik et al. 2016; Das et al. 2018; Barik et al. 2020). The genetic diversity and structure of the population need to be studied in association mapping for detecting marker-trait association which could be useful for trait enhancement in molecular breeding programs. For detecting a perfect marker-phenotype association, the population should not show spurious association or unequal relatedness within the population (Mohapatra et al. 2017; Pandit et al. 2017; Pradhan et al. 2020). Therefore, population structure (Q) with relative kinship (K) analyses is used to check and correct the panel population composition for linkage 
disequilibrium (LD) mapping analyses (Yu et al. 2006; Pandit et al. 2017). Thus, association estimate based on both the models of General linear model (GLM) and Mixed linear model (MLM) is considered appropriate for mapping complex traits that have shown to perform better than other model analysis. However, limited information is available on genetic analysis of physiological parameters related to seed vigour in rice utilizing SSR markers in a variable natural population.

Therefore, in the present investigation, association mapping of physiological parameters with 109 SSR markers was performed in a representative population shortlisted through phenotyping of 15 physiological traits namely electrical conductivity (EC), RI, GP, GI, SDW, RL, SL, SVI I, SVI II, rate of root growth (RRG), RSG, RPE, relative growth rate relative growth rate (RGR), AGR and MGR from 250 germplasm lines. The study will reveal the population genetic structure, diversity and candidate genes/QTLs involved in the 15 physiological traits associated with seed vigour in rice.

\section{Material And Methods}

\section{Seed material}

The freshly harvested seeds of 250 diverse germplasm lines collected from five states viz., Assam, MP, Kerala, Odisha and Manipur of India were used for association mapping of physiological growth parameters. The germplasm lines of Odisha state were from the Jeypore tract, the secondary center of origin of rice and known for availability of rich diversity of rice. All the germplasm lines were collected from Gene bank, ICAR-NRRI, Cuttack and grown during wet season, 2017-18 (Supplemental Table 1). The harvested seeds were used for estimation of 15 physiological growth parameters after a storage period of three months to overcome the seed dormancy. A panel population was developed and raised during wet seasons of 2018-19 and 2019-20. The panel population (96) is highlighted in the Supplementary Table 1 were used for mapping of physiological traits (Table 1).

\section{Phenotyping of physiological traits}

Seed physiological characteristics such as electrical conductivity, rate of imbibition, germination \%, germination index, root length, shoot length, seedling dry weight, seed vigour index, seed vigour index, rate of root growth, rate of shoot growth, rate of plumule elongation, relative growth rate, absolute growth rate and germination rate were estimated for the mapping study.

Seed physiological traits were estimated by sowing 50 seeds in three replications following top of paper method by incubating at $30^{0} \mathrm{C}$. The $\mathrm{EC}$ was determined by measuring the conductivity of the seed leachate of 50 seeds soaked in $150 \mathrm{ml}$ distilled water for 24 hrs at $30^{\circ} \mathrm{C}$ and expressed as $\mu \mathrm{mhos} \mathrm{cm}^{-1}$. Rate of imbibition of the germplasm lines was determined as increase in volume of seed after soaking the seed in water for 24 hours. The percentage of germinated seeds at $10^{\text {th }}$ day was referred to as the final germination percentage. GI was calculated by adopting the method of Maguire, 1962 . RL and SL were measured at $10^{\text {th }}$ day of germination and expressed in $\mathrm{cm}$. The increase in plumule length per day were considered as rate of plumule elongation and expressed in $\mathrm{cm}$ day ${ }^{-1}$. The increase in root and shoot length per day recorded at $7^{\text {th }}$ day and $10^{\text {th }}$ day of germination were considered as RRG and RSG and expressed in $\mathrm{cm}$ day $^{-1}$. AGR was calculated as per procedure of Reford (1967) and RGR was determined following the procedure of Fisher (1921). MGR was computed by adopting the procedure of Zuo et al. 2018. The seedlings used for recording rate of growth were subsequently oven dried at $70{ }^{0} \mathrm{C}$ for 48 hours after removing the cotyledon and seedling dry weight was expressed in gram per seedling. Seed vigour indices (SVI I and II) were calculated using the formula suggested by Abdul-Baki and Anderson (1973). For estimating all the physiological traits except EC, RI and SG (50 seeds in each three replication) observations were recorded on five seedlings selected from each replication and averaged to get the value of each replication.

Analysis of variance (ANOVA) for individual character including the estimation of mean, range, and coefficient of variation (CV \%) were estimated by using Cropstat software 7.0. Pearson's correlation coefficients were analyzed to find out the relationship among the various physiological traits, based on the mean values of the 96 genotypes and presented in correlation matrix heatmap. The mean estimates of the 15 physiological parameters were classified into 4 groups as very high, high, medium and low value containing germplasm lines for this study.

Genomic DNA isolation, PCR analysis and selection of SSR markers

Genomic DNA of the germplasm lines was extracted from 15 days-old plant by adopting CTAB method (Murray and Thompson, 1980). The 109 SSR (simple sequence repeat) markers were taken from the data base available in the public domain (Supplementary Table 2). The isolated DNA was quantified by resolving the DNA fragments in gel electrophoresis. PCR analysis was done using the markers selected based on position covering all the chromosomes to illustrate the diversity and to identify the polymorphic loci among the 96 rice germplasm lines (Table 1). Conditions of PCR reaction was set to initial denaturation step $\left(2 \mathrm{~min}, 95^{\circ} \mathrm{C}\right)$, followed by 35 cycles of denaturation $\left(30 \mathrm{~s}, 95^{\circ} \mathrm{C}\right)$ and annealing/extension $\left(30 \mathrm{~min}, 55^{\circ} \mathrm{C}\right)$, extension $\left(2 \mathrm{~min}, 72^{\circ} \mathrm{C}\right)$, final extension $\left(5 \mathrm{~min}, 72^{\circ} \mathrm{C}\right)$ and store at $4^{\circ} \mathrm{C}$ (infinity). The PCR products were electrophoresed using $2.5 \%$ agarose gel containing $0.80 \mathrm{~g} \mathrm{ml} \mathrm{l}^{-1}$ ethidium bromide. To determine the size of amplicons, $50 \mathrm{bp}$ DNA ladder was used. The gel was run at $2.5 \mathrm{~V} \mathrm{~cm}^{-1}$ for 4 hrs and photographed using a Gel Documentation System (SynGene).

\section{Molecular data analysis}

Data scoring was carried out from the presence or absence of amplified products obtained on the basis genotype-primer combination. A binary data matrix was used as discrete variables for the entry of our result data. Software, 'Power Marker Ver3.25' was used to analyze the parameters namely polymorphic information content (PIC), observed heterozygosity (H), number of alleles (N), major allele frequency (A) and gene diversity (GD) for each SSR locus (Liu and Muse 2005). A Bayesian model based clustering approach STRUCTURE 2.3.6 software was used to analysis genetic data and obtain population structure (Pritchard et al. 2000). To derive the ideal number of groups (K), STRUCTURE software was run with K varying from 1 to 10 , with 10 iterations for each K value. A high throughput parameter set of burn-in period of the 150,000 followed by 150,000 Markov Chain Monte Carlo (MCMC) replications was adapted during the 
running period. Highest value of $\Delta \mathrm{K}$ was pick up from Evanno table used to detect the subpopulation groups from the panel of populations in the next step. The maximal value of $\mathrm{L}(\mathrm{K})$ was identified using the exact number of sub-populations. The model choice criterion to detect the most probable value of $\mathrm{K}$ was $\triangle \mathrm{K}$, an ad-hoc quantity related to the second-order change of the log probability of data with respect to the number of clusters inferred by STRUCTURE (Evanno et al. 2005). Structure Harvester was used for estimation of the $\Delta \mathrm{K}$-value as function of $\mathrm{K}$ showing a clear peak as the optimal K-value (Earl and Vonholdt, 2012). The principal coordinate analysis of all the genotypes and unweighted neighbor joining unrooted tree for NEl coefficient dissimilarity index (Nei, 1972) with bootstrap value of 1,000 were obtained by using DARwin5 software (Perrier and Jacquemoud-Collet, 2006). The presence of molecular variance across the whole population, within a population and between the sub-population structures $\left(F_{I T}, F_{I S}, F_{S T}\right)$ was calculated by the deviation from Hardy-Weinberg expectation and estimated through Analysis of molecular variance (AMOVA) using GenAIEx 6.5 software. All the detailed protocols of the above mentioned softwares were described in earlier publications (Pradhan et al. 2016; Pandit et al. 2017; Pandit et al. 2020; Pradhan et al. 2020).

Software, "TASSEL 5.0" was used to analyze the marker-trait association for mapping study of the seed vigor traits in rice. General linear model and Mixed linear model in TASSEL 5.0 were used to perform the genetic association between the phenotypic traits and molecular markers (Bradbury et al. 2007). By considering the significant $p$-value and $r^{2}$ value convincing associated markers were identified. The associations of markers were further confirmed by the $\mathrm{Q}-\mathrm{Q}$ plot generated by the software. Linkage disequilibrium plot was obtained using LD measured $\mathrm{r}^{2}$, between pair of markers is plotted against the distance between the pair. Also, the accuracy of the marker-trait association by estimating the FDR adjusted p-values (q-values) using R software as described in the earlier publications (Pandit et al. 2017; Pradhan et al. 2020).

\section{Results}

\section{Phenotyping of the population for physiological traits in rice}

The mean values of 250 genotypes for 15 physiological traits viz., EC, RI, G,GI, RL, SL, SDW, SVI-I, SVI-II, RRG, RSG, RPLE, RGR, AGR, and MGR related to seed vigour were estimated during wet seasons of 2019 and 2020 (Supplementary Table 1). Significant differences were noticed among the germplasm lines for these 15 traits. The frequency distribution of the 250 germplasm lines were broadly classified into 4 groups each for the 15 physiological parameters (Fig. $1 \mathrm{~A}$ C). The distribution of germplasm lines into various groups were categorized into groups or subpopulations (Fig. 1). A representative panel population containing 96 genotypes was developed from the original population by shortlisting germplasm lines from all the phenotypic groups of each parameter (Table 1; Fig. 2). The mean values of the 15 physiological traits estimated from the studied panel population also showed significant variation among the genotypes for each trait (Table 1). High to very high estimates of seed vigour index I was observed in the germplasm lines MNPAC9005, MNP-AC9006, MNP-AC9021, MNP-AC9038, MNP-AC9043, JBSAC20282, JBSAC20328, JBSAC20362, JBSAC20371, JBSAC20389, JBSAC20770, JBSAC20920, Kantakapura,

Kantakaamala, Kapanthi, Champaeisiali, Gondiachampeisiali, Kaniar, Adira-2PallakadR3, Pk-21, and AC-10187. High seed vigour index-II were estimated from the lines MNP-AC9030, MNP-AC9038, MNP-AC9043, MNP-AC9044A, MNP-AC9058, MNP-AC9063, MNP-AC9065, MNPAC9090, MNPAC9093, JBSAC20282, JBSAC20328, JBS-AC20362, JBS-AC20371 and JBS-AC20389 (Table 1). The germplasm lines MNP-AC9021, JBS-AC20317, JBS-AC20328, JBS-AC20362, JBS-AC20371, JBS-AC20389, Adira-2PallakadR3, Pk-21, Shayam, Basumati-B, Sugandha-2 and Chatuimuchi showed high germination index. High values for seedling dry weight were recorded from the germplasm lines MNP-AC9028, MNP-AC9030, MNP-AC9035, MNP-AC9043, MNP-AC9058, MNP-AC9063, MNPAC9065, MNP-AC9090, and MNP-AC9093. Very high RSG estimates was noticed in MNP-AC9030, MNP-AC9035, MNP-AC9038, Kapanthi, Pk-21 while MNPAC9044A, JBS-AC20423, JBS-AC20920, Champaeisiali, Magra, Balisaralaktimachi-k, AC-6023, AC-6183, AC-10162, AC-10187 exhibited high rate of root growth. Very high relative growth rate was recorded from the genotypes viz., MNP-AC9030, MNP-AC9038, MNP-AC9043, MNP-AC9044A, Kundadhan, Latamahu, Laxmibilash, Kanakchampa, Magura-s , PK-18Ezhoml-2, PK-24Jyothi, PK-25Jaya, PK-33D1, AC-5993, AC-6027, AC-6172, AC-7134 and AC-7269s. Germplasm lines Kantakapura, Champaeisiali and Latamahu showed very high estimates for rate of plumule elongation. Very high shoot length was recorded from MNP-AC9030, MNP-AC9035, MNP-AC9038, MNP-AC9043, MNP-AC9044A, JBS-AC20282 and JBS-AC20770. Very high electrical conductivity was detected from the genotypes, MNP-AC9030, JBS-AC20282, JBS-AC20845, JBS-AC20907 and AC-7008. Germplasm lines namely MNP-AC9038, MNP-AC9043, JBS-AC20282 and BS-AC20845 were categorized for very high Rate of imbibitions. In addition, very high seedling root length was recorded from the germplam lines MNP-AC9005, MNP-AC9076A, kapanthi and Champaeisiali. Also, very high estimates of rate of plumule elongation were observed in the germplasm lines namely Kantakapura, Champaeisiali and Latamahu. MNP-AC9030, MNP-AC9035, MNP-AC9038, MNP-AC9043, MNP-AC9044A, JBS-AC20282 and JBSAC20770 had high seedling shoot length in the panel population. The germplasm lines possessing high values of multiple physiological traits for $\geq 10$ were in MNP-AC9005, MNP-AC9006, MNP-AC9038, MNP-AC9043, MNP-AC9044A, JBS-AC20282 and JBS-AC20328 (Table 1).

\section{Relatedness among germplasm lines for physiological traits through genotype-by-trait biplot analysis}

The scatter diagram was plotted taking the first two principal components to generate genotype-by-trait biplot graph for the 15 physiological traits estimated from the 96 genotypes present in the panel (Fig. 3). The first and second principal components showed 99.651 and 0.2204 of the total variability with eigen value of 102641 and 227.016, respectively (Supplementary Fig. 1). SVI-I contributed maximum diversity among the 15 physiological parameters followed by GI and SVI-II for the panel population based on the principal component analysis (Fig. 3). The scattering pattern of genotypes in the 4 quadrants indicated that genotypes containing high estimates of parameters are placed in opposite direction of the quadrant 1 and II. Higher estimates of physiological parameters containing genotypes have been encircled in the figure (Fig. 3). The top right (Ist quadrant) and bottom right ( ${ }^{\text {nd }}$ quadrant) accommodated majority of the genotypes containing high estimates of physiological parameters. The $3^{\text {rd }}$ (bottom left) quadrant kept most of the moderate value containing physiological parameters while the $4^{\text {th }}$ quadrant (top left) accommodated majority of poor in values of the physiological parameters (Fig. 3).

\section{Nature of association among seed vigour related traits}

The association among 15 physiological traits revealed a strong positive correlation ( $\geq 00.7$ ) of SVI I with GI and GP; SVI II with SDW; GP with GI, and AGR with RRG and RSG (Fig. 4). Moderate positive correlation (r: 0.5-0.7) of SVI I with RL and SL; SVI II with GI,SVI I and GR; RI with EC; SL with RI and RL; RRG with RL; 
RSG with SL; AGR with RL, SL; MGR with GI, SDW, SVI II were observed. Weak positive correlation ( $r<0.5)$ was noticed for SVI I with RI, RRG, RSG, AGR and MGR; SVI II with RI, GP, RL and SL; RRG with SL, RSG and AGR; RRG with SL; RSG with GI, RL, SDW and RRG; RPE with RL and SL; AGR with RI, SDW; MGR with Germ, RL, SL, RSG. However, weak negative correlation was estimated for RGR with GI, GP and SVI I (Fig. 4).

\section{Genetic diversity parameters analysis}

The constituted panel containing 96 genotypes from the original population which exhibited wide variation for the physiological parameters was genotyped using 109 molecular markers. The gene diversity, loci used for genetic diversity and other diversity related parameters are presented in Table 2. A total of four hundred four markers alleles were obtained with average value of 3.07 alleles per locus. The range of alleles per locus varied from 2 to 7 per marker showing the highest number of alleles by RM220, RM448 and RM493 in the studied panel for the physiological parameters. The average value of the major allele frequency of the parameters linked to the polymorphic markers was observed to be 0.578 which varied from 0.292 (RM488 and 493 ) and 0.958 (RM22034) (Table 2). The range for PIC value was estimated to be from 0.141 (RM315 and 6054) to 0.771 (RM493) with mean value of 0.477 . The observed average heterozygosity $(\mathrm{Ho})$ in the population was 0.117 which varied from 0.00 to 0.958 . The gene diversity ( $\mathrm{He}$ ) in the panel ranged from 0.061 (RM556) to 0.799 (RM493) showing a mean value of 0.533 .

\section{Population Genetic Structure Analysis}

The genotypes in the panel exhibiting variation for the studied physiological parameters were evaluated for genetic structure adopting probable subpopulations $(\mathrm{K})$ and selecting higher delta K-value estimated by STRUCTURE 2.3.6 software. The delta $\mathrm{K}$ value is related to the rate of change in the log probability of data between successive $\mathrm{K}$ values. It categorized the genotypes into two sub-populations (Fig. 3A; Fig.3B) with a high $\Delta \mathrm{K}$ peak value of 264.2 at $\mathrm{K}=2$ among the assumed $\mathrm{K}$ (Fig. 5). The proportions of genotypes in the inferred clusters were 0.875 and 0.125 in subpopulation 1 and subpopulation 2 , respectively. However, the two subpopulations did not show correspondence well with the studied physiological parameters. Hence, next peak at the $\Delta \mathrm{K}$ peak was considered and the population was categorized into 6 subpopulations. The proportions of genotypes in the inferred clusters were $0.179,0.211,0.258$, $0.081,0.181$ and 0.091 for the sub-population $1,2,3,4,5$ and 6 , respectively. The fixation index (Fst) values were $0.278,0.254,0.201,0.332,0.206$ and 0.507 for the sub-population $1,2,3,4,5$ and 6 , respectively. The expected average distances or heterozygosity were $0.342,0.348,0.366,0.390,0.373$ and 0.331 in the sub-population $1,2,3,4,5$ and 6 , respectively. The genotypes with $\geq 80 \%$ ancestry value were categorized for that subpopulation (Table 3 ; Fig. 5).

The physiological parameters showed a relatively fair correspondence at $\mathrm{K}=6$ with the structure subpopulations present in the panel population. Majority of the moderate to high seed vigour showing germplasm lines present in the subpopulations SP2 and SP6 while poor vigour containing lines were in subpopulation SP4 and SP5. The panel also showed a low alpha value (alpha $=0.0591$ ) by the structure analysis at $\mathrm{K}=6$. Positively skewed leptokurtic distributions were observed for mean alpha-value, Fst3, Fst4 and Fst5 while mesokurtic distributions detected for Fst1, Fst2 and Fst6 for the panel population showing a distinct variation in the distribution among the Fst values (Supplementary Fig. 2).

\section{Molecular variance (AMOVA) and LD decay plot analysis}

The closely related plants in a population are clustered into isolated groups and form various subpopulations. Genetic variations between and within the subpopulations at $\mathrm{K}=6$ were detected through analysis of molecular variance (AMOVA) (Table 4). The genetic variations obtained between and within at $\mathrm{K}=6$ was computed to be $12 \%$ among the populations, $67 \%$ among individuals and $21 \%$ variation within individuals of the panel population. Deviation from HardyWeinberg's prediction was calculated from Wright's $F$ statistics estimates. Different parameters like uniformity of individual within the subpopulation $\left(F_{I S}\right)$ and individual within the total population $\left(F_{I T}\right)$ were estimated for differentiation of population. The $F_{I T}$ and $F_{I S}$ values of total population and within population based on 109 loci were 0.791 and 0.763 , whereas $F_{S T}$ was 0.118 between the two subpopulations. Fst is estimated to measure the population differentiation or the subpopulations within the total population. The Fst values of each sub-population and their distribution pattern showed a clear differentiation between the six sub-populations from each other (Supplemental Fig. 2).

The nonrandom association of alleles at different loci is successfully utilized for marker-trait association study. The LD decay rate is important factor for getting marker-trait association. The decay rate will facilitate the discovery of reliable markers associated with the physiological parameters and will facilitate the discovery of new genes or allelic variants controlling these traits. Syntenic 2 was used to plot the LD decay of the population against the physical distance in million base pair (Fig. 6). Tightly linked markers have the highest $r^{2}$ and average $r^{2}$ rapidly decreases as linkage distance increases. There was a sharp decline in LD decay for the linked markers at 1-2 mega base pair and thereafter a very slow and gradual decay was noticed. Overall, it is clear that LD decay occur for the physiological parameters.

\section{Genetic relatedness among genotypes by principal coordinates and cluster analyses}

The two dimensions diagram for principal coordinate analysis ( $P C O A)$ is drawn based on 109 markers which grouped the genotypes as per the genetic relatedness among them (Fig. 7). The component 1 accounted for $11.04 \%$ inertia and component 2 for $6.71 \%$ of total inertia. The panel genotypes were placed in various spots of the 4 quadrants which formed three major groups (Fig. 7). A total of 30, 46,11 and 9 number of germplasm lines were distributed in the $1^{\text {st }}$, $2^{\text {nd }}, 3^{\text {rd }}$ and $4^{\text {th }}$ quadrant, respectively. The genotypes belonging to the 6 different sub-populations are grouped in different quadrants. The $1^{\text {st }}$ quadrant genotypes are divided into 3 groups whereas the $2^{\text {nd }}$ quadrant genotypes are divided into two groups of which one group is closer to axis 1 and another is to axis 2 . This $2^{\text {nd }}$ group genotypes closer to axis2 are admix type depicted in black colour (Fig. 7).

The majority of the germplasm lines containing high to very high mean values of physiological traits were placed in the 1st (top right) and 2nd (bottom right) quadrants of the PCOA. The PCoA distributed the genotypes in the four quadrants forming 7 clusters including the admix type subpopulation. The subpopulations clustered by PCoA are encircled in the figure and showed correspondence with population structure (Fig. 7). Germplasm lines having high to 
very high mean values of physiological traits placed in the quadrant II were ARS-AC-6221, MP-Joha, KE-Adira-2-Pallakad-R3, KE-PK-18-Ezhoml-2, KE-PK-14Vachaw and KE-PK-24-Jyothi. Genotypes namely OD-Landi, OD-Balisaralaktimachi, OD-Kaniar, OD-Kanakchampa, ARS-AC-6023, ARS-AC-6172, MNP-AC-9030, KE-PK-19-Cheruvirippu, JBS-AC-20614, MNP-AC-9005, JBS-AC-20371 and JBS-AC-20423 were observed in the quadrant I. Quadrant III consisted of genotypes mostly from SP4 subpopulation. Majority of the germplasm lines in quadrant IV were from SP6 subpopulation. Majority of the admix genotypes were found in quadrant I and II.

Six sub groups were observed in the dendrogram based on the mean values of studied physiological parameters (Fig. 8A). A total of $15,4,11,21,19$ and 26 genotypes were distributed in the cluster I to VI, respectively. Cluster VI was biggest cluster which accommodated 26 germplasm lines while cluster II was smallest with only 4 genotypes. The germplasm lines present in sub-population 2 of genetic structure were observed in group 6 of the dendrogram. Similarly, four genotypes of structure subpopulation 1 were in the group 4 of the dendrogram. Admix genotypes obtained from the structure were found in all the groups of this phenotype cluster except group 4.

The cluster analysis discriminated the germplasm lines on the basis of genotyping of 109 SSR markers and placed the genotypes into different clusters which corresponded with the studied physiological parameters. The unweighted-neighbour joining tree differentiated the genotypes into 6 different clusters (Fig. 8 ). Clusters $\mathrm{SP}_{1}$ was differentiated from $\mathrm{SP}_{3}$ by the presence of high estimates of root length and rate of plumule in it whereas Seedling dry weight \& Seed vigour index II were rich in $\mathrm{SP}_{3} . \mathrm{SP}_{2}$ and $\mathrm{SP}_{6}$ had accommodated majority of germplasm lines containing high values for the studied parameters except Seedling dry weight in $\mathrm{SP}_{2}$ and germination \% in $\mathrm{SP}_{6}$. $\mathrm{Sp} 4$ was discriminated from others based on absence of germplasm lines containing high estimates for germination rate and seed vigour index II while root length and seedling dry weight were absent in $\mathrm{SP}_{5}$.

\section{Association of marker alleles with physiological parameters in rice}

Association of molecular markers with 15 physiological parameters was computed using Mixed Linear Model (MLM/ K+Q model) and Generalized Linear Model (GLM) by TASSEL 5 software. The marker-trait comparisons were subjected to filtration at less than $1 \%$ error i.e. $99 \%$ confidence ( $p<0.01$ ). Twelve parameters showed significant associations with markers using both the models at $p<0.01$. A total of 112 and 93 significant marker-trait associations were detected by GLM and MLM, respectively at $p<0.01$. The marker $R^{2}$ values computed by GLM approach was from 0.565 to 22.7 while the range was 0.7009 to 0.175 by Mixed Linear Model (Supplementary Table 3). Significant marker-trait associations were detected for G1 with 5 markers; SVI-II, RSG and MGR with 3 markers; GP, RGR and RP with 2 markers, and RI, RL, SVI, AGR and RRG with 1 marker by both GML and MLM models at $p<0.01$. Considering trimming at $r^{2}>0.10$ and $p<0.01,6$ markers exhibited associations with 4 physiological parameters namely GI with RM225 and RM502; GP with RM225 and RM502; SVI with RM5638 and RP with RM220 (Table 5; Supplemental table 4). The Q-Q plot also confirmed the association of these markers with the associated physiological traits in rice (Fig...).

Four markers showed significant association with GI detected by GLM and MLM models at $p<0.01$. The genomic regions controlling the trait, GI was detected on chromosome 1, 8, 11 and 12 associated by markers RM5638, RMRM502, RM229 and RM20A, respectively. Among the four markers, RM502 showed highest marker $\mathrm{R}^{2}$ value of 0.227 analyzed by GLM and 0.175 by MLM. Three markers namely RM5638, RM14723 and RM7003 located at 204,86 and 132 cM positions on chromosome 1, 3 and 12, respectively were associated with the parameter, SVII. RSG was detected to be associated with RM 6547 , RM3701 and RM7003 present on chromosome 1, 11 and 12, respectively. MGR was found to be controlled by the QTLs present on the chromosome 1, 8 and 9 which showed associations with markers RM220, RM502 and RM201, respectively. QTLs for Germination \% showed significant associations with RM225 on chromosome 6 and RM502 on chromosome 8. The parameter, RPE was detected to be located on chromosome 1 showing association with RM220 and RM403. Relative growth rate exhibited association with RM468 and RM3701. Marker RM256 showed significant association with RRG and AGR. Significant associations of markers RM248, RM229 and RM5638 with RI, RL and SVI, respectively were detected by both the models. Marker RM256 was strongly associated with parameters, RRG and AGR. In addition, RI, RL and SVI showed significant associations with RM248, RM229 and RM5638, respectively (Table 5). The Q-Q plot also confirmed the associations of these markers with the estimated physiological parameters in rice (Fig. 9).

Common markers were observed to be associated with different physiological parameters in rice. Few markers showed significant associations with two physiological parameters namely RM220 with RP and AGR; RM225 with GI and GP; RM229 with GI and RL; RM256 with AGR and RRG; RM3701 with RSG and RGR, and RM7003 with SVII and RSG by both the models at < 1\% error. Also, marker RM602 showed significant associations with 3 traits namely GI, GP and MGR. In addition, RM5638 also associated with 3 parameters namely GI, SVI and SVII by both the models at p<0.01 (Table 5).

\section{Discussion}

The germplasm lines present in the panel population were significantly different from each other with respect to the 15 studied physiological traits (Table 1). Higher magnitude of correlation coefficients was estimated in many studied physiological parameters. This revealed the improvement of seed vigour through the associated traits based on the values of the coefficients of the correlated parameters and availability of higher genetic variations in the population (Table 4). Earlier reports of high variations and genetic advance for many traits were published by many researchers (Bose et al. 2007; Zhao et al. 2013; Anandan et al. 2016; Pradhan et al. 2016; Pandit et al. 2017; Huang et al. 2015; Pradhan et al. 2019b). The existence of diversity based on 109 markers and phenotypic variations of the 15 physiological traits showed clear cut differentiations in the studied population (Table 2). A moderate to high PIC value and more alleles in the population revealed about better informative markers and for use in the breeding program. The germplasms used in this study were collections from the states known for existence of rich rice genetic diversity (Sahoo et al. 2020). Germplasm lines from Jayapur tract of Odisha, the secondary centre of origin were also included in this study. The germplasm lines having high values of multiple physiological traits for $\geq 10$ were MNP-AC9005, MNP-AC9006, MNP-AC9038, MNP-AC9043, MNP-AC9044A, JBS-AC20282 and JBS-AC20328. These germplasm lines will be potential donors for seed vigour trait in breeding programs (Table 1). Hence, it is expected that breeding programme with inclusion of parental lines from this population may be effective for seed vigour and its related traits. Many publications on existence of genetic diversity are reported in rice (Bose et al. 2005; Shukla et al. 2006; Chen et al. 2011; Zhang et al. 2011; Singh et 
al. 2013; Pandit et al. 2016; Pradhan et al. 2020). Six structure groups and presence of different Fst values supported the existence of various LD group in the population. A low alpha value and existence of many admix type germplasm lines in the population revealed that the trait seed vigour evolved from single source and subsequently formed different admix genotypes with different ancestry value during evolutionary process. A good correspondence of genetic structure and physiological parameters was previously published by earlier workers (Anandan et al. 2016; Sahoo et al. 2020). Additionally, publications on phenotype of various traits and structure correlation have been published by many workers (Pradhan et al. 2016; Anandan et al. 2016; Pandit et al. 2017; Zhang et al. 2012; Huang et al. 2011; Zhao et al. 2013; Huang et al. 2015; Pradhan et al. 2019b; Pradhan et al. 2020; Sahoo et al. 2020).

Twelve physiological parameters influencing seed vigour were found to be associated with 10 SSR markers analyzed by both GLM and MLM approaches (Table 5). The markers detected to be associated by both the models at $p<0.01$ and low ' $p$ 'value are considered to be very robust and useful for seed vigour improvement program. Hence, markers namely RM5638, RMRM502, RM229 and RM20A for GI; RM14723, RM7003 and RM5638 for SVII; RM 6547, RM3701 and RM7003 for RSG; RM220, RM502 and RM201 for MGR; RM225 and RM502 for germination \%; RM220 and RM403 on chromosome 1 for RPE; RM468 and RM3701 for RGR; RM256 for RRG and AGR; RM248, RM229 and RM5638 for RI, RL and SVI, respectively are useful in molecular breeding for improvement of seed vigour in rice (Table 5). Q-Q plot also confirmed the associations of these markers with various seed vigour influencing traits in rice (Fig. 9).

Many QTLs controlling germination \% were reported by earlier researchers in rice (Zhang et al. 2005; Wang et al. 2010; Li et al. 2013; Liu et al. 2014; Jiang et al. 2017; Wang et al. 2017; Jin et al. 2018; He et al. 2019). As per earlier mapping results, germination \% is controlled by QTL, qLTG-3-1 (Fujino et al. 2008). Another QTL, qGP-9 for the trait was localized to $92.8 \mathrm{~kb}$ between two STS markers interval of P6 and P8 (Li et al. 2017). OsIPMS1 controls seed vigor in rice which is correlated with starch hydrolysis, glycolytic activity and energy levels in germinating seeds (He et al. 2019). As per report of Wang et al. 2010, the QTLs for GP were located on chromosome 6 at 123-132 cM and chromosome 8 at 23.4-34.6cM positions. In our investigation, the RM225 and RM502 were significantly associated with germination \% were located on chromosome 6 at $92 \mathrm{cM}$ and chromosome 8 at $177 \mathrm{cM}$, respectively detected by both the models of GLM and MLM. Therefore, these locations are different from the genes reported by Fujino et al. 2008, Jiang et al. 2017, Liu et al. 2014, Li et al. 2017, Wang et al. 2017, Jin et al. 2018 and He et al. 2019. Hence, the two QTLs detected for the trait in this mapping study were novel QTLs and designated as qGP6.2 and qGP8.2. Rate of plumule elongation was observed to be associated significantly with markers RM220 and RM403 on chromosome 1 and 8 , at $242 \mathrm{cM}$ and $183 \mathrm{cM}$ positions, respectively. These two QTLs designated as qRPE1.1 and qRPE8.1 were considered as novel QTLs as no gene(S)/QTLs were reported at these locations from other studies in rice. Germination rate in rice seed is controlled by the QTLs present on chromosome 3, 5, 6 and 7 (Cui et al. 2002). The QTL present on the chromosome 1, qGR1 reported for germination rate, is located at 137.5-156.8cM placed away from the detected QTL (Wang et al. 2010). For germination rate, we detected the QTL at $240 \mathrm{cM}$ position on chromosome 1. The detected novel QTL is designated as $q G R 1.2$ is located on chromosome 1 at $240 \mathrm{cM}$ position. Two QTLs for GR were located on chromosome 8 at $146 \mathrm{cM}$ and 153cM positions reported (Jin et al. 2018). The QTL detected for GR in the present investigation on chromosome 8 was at $177 \mathrm{cM}$ position. Hence, the novel QTL controlling germination rate is designated as $q G R 8.3$. The QTL for GR present on chromosome 9 was not reported in earlier studies and hence the QTL is novel which is designated as $q G R 9.1$. The QTL for germination index were located on chromosome 1, 3, 7, 8 and 10 (Liu et al. 2014). The detected QTLs for the trait on chromosome 6, 11 and 12 were not reported in earlier studies. Hence, the three novel QTLs are designated as $q G / 6.1, q G / 11.1$ and $q G / 12.1$. The QTL detected on chromosome 1 were reported earlier by Wang et al. 2010 and Liu et al. 2014. As per Wang et al. 2010, the position of $q G / 1.1$ was at 88.8-111.5 cM and Liu et al. 2014 located at 52.1-54.2 cM. In the present investigation, we detected the QTL on chromosome 1 at 284cM position. The detected novel QTL is designated as $q$ G/1.2 is located on chromosome 1 . In addition, another QTL reported on chromosome 8 for this parameter was located at 92.2-116.7 cM position (Liu et al. 2014). We detected a QTL on chromosome 8 at $177 \mathrm{cM}$ position. Hence, the detected QTL is a novel one and designated as qG/8.1. The QTLs for seedling root length on chromosome 1, 2, $3,5,6,7,8,9,10$ and 12 reported by different workers are different from the present investigation detected QTL for root length which is located on chromosome 11 (Cui et al. 2002; Zhang et al. 2005; Zhang et al. 2017; Jin et al. 2018; To et al. 2019; Zhao et al. 2019; Yang et al. 2020). The QTL controlling this trait located on chromosome 12 was within G193-RG574 and linked to RM3455 and RM1065 (Zhang et al. 2005; To et al. 2019; Zhao et al. 2019). The root length-marker linkage reported by Madhuri et al. 2016 is exactly at the same location on the chromosome 11. Hence, this QTL which controlled the seedling root length is validated in the panel population and will be useful in breeding program or improvement of the trait.

Genetic analysis for seedling growth parameters were reported by many workers (Huang et al. 2004; Zhang et al. 2005; Wang et al. 2010; Cordero-Lara et al. 2016; To et al. 2019; Zhao et al. 2019). Relative shoot length showed association with the markers RM3701, RM7003 and RM6547 analyzed by both the models. Mapping results of Han et al. 2002 showed the location of the QTL on chromosome 1 within 117-133.4 cM. We mapped the QTL on the same chromosome but at $145 \mathrm{cM}$ position. Results obtained from Cao et al. 2002, Abe et al. 2012, Dang et al. 2014 and Anandanan et al. 2016, also reported the QTL for the trait on different chromosomes. Hence, the QTL located at $145 \mathrm{cM}$ position is a novel QTL and designated as qRSG1.2. Another QTL on chromosome 12 at 101-107 cM position was reported by Han et al. 2007 but we detected a QTL for the trait at $132 \mathrm{cM}$. The novel QTL detected by us is designated as qRSG12.2. Relative growth rate was mapped by Kato et al. 2007 on chromosome 4 and 7 within marker interval of RM8213-RM335 and RM8249-RM5120, respectively. The detected QTL in this investigation were located on chromosome 3 and 11. The detected QTLs are novel QTLs and designated as $q R G R 3.1$ and $q R G R 11.1$. Three QTLs located on chromosome 2, 3 and 12 for absolute growth rate by Bharamappanavara et al. 2020. We detected the QTL on chromosome 8 which is not reported in earlier studies. This novel QTL is designated as qAGR8.1. The trait, seed vigour index was reported from linkage analysis of Zhang et al. 2005 in which RM249 on chromosome 5 and RM225 on chromosome 6 controlled the physiological parameter. As per report of Diwan et al. 2013, qVI on chromosome 5 was linked with the trait. Anandan et al. 2016 found association of seed vigour index with marker, RM341 on chromosome 2. In our investigation, markers RM5638 located on chromosome 1 showed significant associations with SVI and SVII by both the models. No reports are available for these two traits at this location. Theses novel QTLs are designated as qSVI1.1 and qSVII1.1. The other two markers, RM14723 on chromosome 3 and RM7003 on chromosome 12 associated with SVII are not reported in earlier studies and are novel QTLs. These two QTLs are designated as qSVII3.1 and qSVII12.1. The QTL for relative root growth, qRRL-7 was mapped by Masuda et al. 2018 on chromosome 7. In our study, we detected the QTL on chromosome 8 at $97 \mathrm{cM}$ position. No reports are available for RRG at this location and hence this novel QTL is designated as qRRG8.1.

\section{Conclusion}


Improvement of seed vigour trait is possible in high yielding varieties by employing the strong markers detected for the physiological parameters through marker-assisted breeding program. Fifteen physiological traits showed wide variations present in a panel of 96 genotypes which represented 250 germplasm lines. Presence of linkage disequilibrium (LD) was detected in the panel population based on the fixation indices of the subpopulations. Moderate values of gene diversity, polymorphic information content (PIC) and other diversity parameters were estimated from the population by genotyping with 109 SSR markers. The population was classified into subpopulations and sub-clusters showed relation with the genotypes for their physiological traits. A total of 19 novel QTLs controlling different physiological parameters namely $q G P 6.2$ and $q G P 8.2$ for germination \%; qGR 9.1 for germination rate; $q G I$ 1.2, $q G / 6.1$, $q G /$ 8.1, $q$ GI 11.1 and $q G / 12.1$ for germination index; qRPE1.1 and $q R P E 8.1$ for rate of plumule elongation (RPE); qAGR 8.1 for AGR; qRSG1.2 and $q R S G 12.2$ for RSG; qRGR3.1 and qRGR11.1 for RGR; qSVI 1.1 for SVI I; qSVII 1.1, qSVII3.1, and qSVII12.1 for SVI II, and qRRG8.1 were identified. The reported QTL for root length, $q R L 11.1$ was validated in this mapping population. Additionally, QTLs, qRPE8.1 and $q A G R 8.1$ of traits, RPE and AGR; $q G I 6.1$ and $q G P 6.2$ of GI and GP; qGI 11.1 and $q R L 11.1$ of GI and RL; qAGR8.1 and $q R R G 8.1$ of AGR and RRG, and $q R S G 3.1$ and $q R G R 3$. 1of traits RSG and RGR were detected for colocalization or co-inheritance. The traits identified and markers detected in the association analysis will be useful for improvement of seed vigour trait through marker-assisted selection in rice.

\section{Declarations}

Ethics approval and consent to participate: The authors declare that this study complies with the current laws of the country in which the experiments were performed.

Consent for publication: Not applicable

Availability of data and material: The data generated or analyzed in this study are included in this article.

Competing interest:The authors declare no conflicts of interest

Funding:No externally aided funding was utilized for this research work

Authors contribution: SKP and PS conceived the study, DKN, SRB, AB, AS, SP, AM, DS and EP conducted the genotyping work, PS, RB, JM and SKP performed the phynotyping work, SRB and EP analyzed the data, SKP, PS wrote the manuscript, all the authors read and approved the final version.

\section{Acknowledgement}

The authors acknowledge the support of Director, ICAR-National Rice Research Institute, Cuttack for providing all the necessary facilities including the funding for conducting the experiment.

\section{References}

1. Abdul-BakiAA, Anderson JO (1973) Vigour determination of soybean seed by multiple

2. criteria. Crop Science 13: 630-633. doi:10.2135/cropsci1973.0011183X00130006013x

3. Abe A, Kosugi S, Yoshida K, Natsume S, Takagi H, Kanzaki H, Matsumura H, Yoshida K, Mitsuoka C, Tamiru M, Innan H, Cano L, Kamoun S, Terauchi R (2012) Genome sequencing reveals agronomically important loci in rice using MutMap. Nat Biotechnol 30:174-178

4. Allard RW (1960) Principles of Plant Breeding. John Wiley and Sons, Inc., New York

5. $\mathrm{pp} 213-233$

6. Anandan A, Anumalla M, Pradhan SK, Ali J (2016) Population structure, diversity and trait association analysis in rice (Oryzasativa L.) germplasm for early seedling vigour (ESV) using trait linked SSR markers. PLoS One 11(3): 406. DOI: https://doi.org/10.1371/journal.pone.01524 06

7. Barik SR, Pandit E, Mohanty SP, Nayak DK, Pradhan SK, Mohapatra T (2016) Parental polymorphism survey and phenotyping of recombinant inbred lines for reproductive stage drought tolerance parameters in rice. Oryza 53(4):374-384

8. Barik SR, Pandit E, Pradhan SK, Mohanty SP, Mohapatra T (2019) Genetic Mapping

9. OfMorphoPhysiological Traits Involved During Reproductive Stage Drought Tolerance In

10. Rice. Plos One 14(12): e0214979

11. Barik SR, Pandit E, Mohanty SP, Nayak DK, Pradhan SK (2020) Genetic mapping of physiological traits associated with terminal stage drought tolerance in rice. BMC Genet 21:76. https://doi.org/10.1186/s12863-020-00883-x

12. Bharamappanavara M, Siddaiah AM, Ponnuvel S, Ramappa L, Patil B, Appaiah M, Maganti SM, Sundaram RM, Shankarappa SK, Tuti MD, Banugu S, Parmar B, Rathod S, Barbadikar KM, Kota S, Subbarao LB, Mondal TK, Channappa G (2020) Mapping QTL hotspots associated with weed competitive traits in backcross population derived from Oryza sativa L. and O. glaberrima Steud. Sci Rep 10:22103. https://doi.org/10.1038/s41598-020-78675-7

13. Bose LK, Pradhan SK (2005) Genetic divergence in deepwater rice genotypes. Journal of central European agriculture 6(4):635-640

14. Bose LK, Das S, Pradhan SK, Subudhi HN, Singh S, Singh ON (2007) Genetic variability of quality characters and grain yield in lowland rice genotypes of eastern India. Korean journal of breeding science 39(1):39-44

15. Bradbury PJ, Zhang Z, Kroon DE, Casstevens TM, Ramdoss, Y, Buckler ES (2007)

16. Cao W, Jiang D, Wang S, Tian Y (2002) Physiological characterization of rice grown under different water management systems in: Water- wise rice production. IRRI, Phillipinespp 249-257 
17. Chauhan JS, Singh LA, Prasad RS, Pal S (2015) Quality seed: A mega factor in enhancing crop productivity in (ED: Singh, LA) Recent advances in crop physiology. Daya publishing house.Astral International PVT Ltd. New Delhi 2:357-366

18. Chen H, He H, Zou Y, Chen W, Yu R, Liu X, Yang Y, Gao Y, Xu J, Fan L. Li Z, Deng X (2011) Development and application of a set of breeder-friendly SNP markers for genetic analyses and molecular breeding of rice (Oryza sativa L.). TheorAppl Genet 123:869. https://doi.org/10.1007/s00122-011-1633-5

19. Cheng L, Oh SG, Lee DH, Baik HW, Chung HJ (2017) Effect of germination on the structures and physicochemical properties of starches from brown rice, oat, sorghum, and millet. Int J Biol Macromol 105(1):931-939

20. Cui KH, Peng SB, Xing YZ, Xu CG, Yu SB, Zhang Q (2002) Molecular dissection of seedling vigor and associated physiological traits in rice. Theo Appl Genetics 105:745-753. doi:10.1007/s00122-002-0908-2

21. Cordero-Lara KL, Kim H, Tai T (2016) Identification of seedling vigor-associated quantitative trait loci in temperate japonica rice. Plant Breeding Biotechnology 4:426-440

22. Das S, Pandit E, Guru M, Nayak DK, Tasleem S, Barik SR, Mohanty DP, Mohanty SP, Patra BC, Pradhan SK (2018) Genetic diversity, population structure, marker validation and kinship analysis for seedling stage cold tolerance in indica rice. Oryza 55(3):396-405

23. Dang X, Thi TGT, Dong G, Wang H, Edzesi WM, Hong D (2014) Genetic diversity and association mapping of seed vigour in rice (Oryzasativa L.),Planta 239: 1309-1319. DOI: https://doi.org/10.1007/s00425-014-2060-z

24. Diwan J, Channbyregowda M, Shenoy V, Salimath P, Bhat R (2013) Molecular mapping of early vigour related QTLs in rice. Research Journal of Biology $1: 24-30$

25. Daniel OI (2017) Biology of Seed Vigor in the Light of -omics Tools. In Jimenez- Lopez

26. JC(Ed) Advances in Seed Biology 6 DOI: 10.5772/intechopen.71258. Available from

27. https://

28. Dingkuhn M, De J, Sowa, Audeberta Y (1999) relationship between upland rice canopy characteristics and weed competitiveness. Field Crop Res 61:7195

29. EarIDA,VonholdtBM (2012) Structure Harvester: a website and program for visualizing STRUCTURE output and implementing the Evannomethod. Conservation Genetics Resources 4:359-361

30. Evanno G, Regnaut S, Goudet J (2005) Detecting the number of clusters of individuals using

31. the software STRUCTURE: A simulation study. MolEcol 14(8): 2611-2620. PMID: 15969739

32. Finch-Savage WE, Bassel GW (2016) Seed vigour and crop establishment: extending performance beyond adaptation. J Exp Bot 67(3):567-591

33. Fisher RA (1921) Some remarks on the methods formulated in a recent article on 'The quantitative analysis of plant growth'. Ann Appl Biol 7:367-372

34. Fujino K, Sekiguchi H, MatsudaY, Sugimoto K, Ono K, Yano M (2008) Molecular identification of a major quantitative trait locus, qLTG3-1, controlling lowtemperature germinability in rice. Proc of NatlAcadSci USA 105:12623-12628

35. Fukagawa NK, Ziska LH (2019) Rice: Importance for Global Nutrition. J NutrSciVitaminol (Tokyo) 65(Supplement):S2-S3. doi:10.3177/jnsv.65.S2

36. Han B, Xue Y, Li J, Deng XW, Zhang Q (2007) Rice functional genomics research in China. Philosophical transactions of The Royal Society B 362:10091021. doi: $10.1098 /$ rstb. 2007.2030

37. He X, Feng X, Sun D, Liu F, Bao Y, He Y (2019) Rapid and Nondestructive Measurement of Rice Seed Vitality of Different Years Using Near-Infrared Hyperspectral Imaging. Molecules 24(12):2227

38. Huang Li, He H, Chen H, Ren X, Chen Y, Zhou X, Xia Y, Wang X, Jiang X, Liao B, Jiang H (2015)Quantitative trait locus analysis of agronomic and qualityrelated traits in cultivated peanut (Arachishypogaea L.) Theoretical and Applied genetics 128: 1103-1115

39. Huang X, Zhao Y, Wei X, Li C, Wang A, Zhao Q, Li W, Guo Y, Deng L, Zhu C, Fan D, Lu Y, Weng Q, Liu K, Zhou T, Jing Y, Si L, Dong G, Huang T, Lu T, Feng Q, Qian Q, Li J, Han B (2011) Genome-wide association study of flowering time and grain yield traits in a worldwide collection of rice germplasm. Nature Genetics 44(1):32-39. doi: 10.1038/ng.1018. PMID: 22138690

40. Huang ZA, Jiang DA, Yang Y, Sun JW, Jin SH (2004) Effects of Nitrogen Deficiency on Gas Exchange, Chlorophyll Fluorescence, and Antioxidant Enzymes in Leaves of Rice Plants. Photosynthetica 42:357-364. https://doi.org/10.1023/B:PHOT.0000046153.08935.4c

41. Hunter MC, Smith RG, Schipanski ME, Atwood LW, Mortensen DA (2017) Agriculture in 2050: Recalibrating targets for sustainable Intensification. Bioscience 67(4):386-391. https://doi.org/10.1093/biosci/bix010

42. Mohapatra S, Pandit E, Barik SR, Patra BC, Pradhan SK (2017) Genetic diversity and population structure in early duration rice genotypes. Oryza 54(2):158-168. DOI 10.5958/2249-5266.2017.00021.2

43. Jiang L, Shi S, Shi H, Khanzada H, Wassan G, Zhu C, Peng X, Yu Q, Chen X, He X, Fu J, Hu L, Xu J, Ouyang L, Sun X, Zhou D, He H, Bian J (2017) Mapping QTL for seed germinability under low temeperature using a new high density genetic map of Rice. Frontiers in plant science 8:1-9

44. Jie J (2018) QTL Mapping of Seed Vigor of Backcross Inbred Lines Derived FromOryzalongistaminata Under Artificial Aging. Frontiers in Plant Science. 9. 10.3389/fpls.2018.01909

45. Kato Y, Kamoshita A, Yamagishi J, Imoto H, Abe J (2007) Growth of Rice (OryzaSativa L.) Cultivars Under Upland Conditions With Different Levels of Water Supply. Root System Development, Soil Moisture Change and Plant Water Status. Plant Production Science 10(1):3-13. DOI:10.1626/pps.10.3

46. Lee HS, Sasaki K, Higashitani A, AhnSangNag ST (2012) Mapping and characterization of quantitative trait loci for mesocotyl elongation in rice (Oryza sativa L.). Rice 5:13

47. Liu K, Muse SV (2005) Power Marker: an integrated analysis environment for genetic marker analysis. Bioinformatics 21(9):2128-2129 
48. Liu LF, Lai YY, Cheng JP, Wang L, Du WL, Wang ZF, Zhang HS (2014) Dynamic quantitative trait locus analysis of seed vigor at three maturity stages in rice. PLoS ONE 9:e115732

49. Liu L, Lai Y, Cheng J, Wang L, Du W, Wang Z, Zhang H (2014) Dynamic Quantitative Trait Locus Analysis of Seed Vigor at Three Maturity Stages in Rice.PlosOne.9(12):e115732https://doi.org/10.1371/journal.pone.0115732

50. Li L, Liu X, Xie K, Wang Y, Liu F, Lin Q, Wang W, Yang C, Lu B, Liu S, Chen L, Jiang L, Wan J (2013) qLTG-9, a stable quantitative trait locus for lowtemperature germination in rice (Oryza sativa L.). TheorAppl Genet 126:2313-2322. https://doi.org/10.1007/s00122-013-2137-2

51. Madhuri MS, Keshavulu K, Subbarao LV, Senguttuvel P, Sheshumadhav M (2016) Phenotypic and genotypic evaluation of root qtl effects on seedling vigor in rice (effects on seedling vigor in rice (oryza sativa I.) 11(3): 1513-1519

52. Maguire JD (1962) Speed of germination: aid in selection and evaluation for seedling

53. emergence and vigor. Crop Science 2, 176-177. doi:10.2135/cropsci1962.00111

54. X000200020033x

55. Mahender A, Anandan A, Pradhan SK (2015) Early seedling vigour, an imperative trait for direct seeded rice: an overview on physio-morphological parameters and molecular markers. Planta 241:1027-1050

56. Miura K, Lin S, Yano M, Nagamine T (2002) Mapping quantitative trait loci controlling

57. seed longevity in rice (Oryzasativa L.). Theoritical and Applied Genetics104:981-986.doi:10.1007/s00122-002-0872-x

58. Murray MG, Thompson WF (1980) Rapid isolation of high molecular weight plant DNA

59. Nucleic Acids Res 8: 4321-4325. PMID: 7433111

60. Nei M (1972) Genetic distance between populations. Am Nat 106:283-292

61. Perrier X, Flori A, Bonnot F (2003) Data analysis methods. In: Hamon P, Seguin M, Perrier X, Glaszmann JC (eds) Genetic Diversity of Cultivated Tropical Plants. Science Publishers, Montpellier, pp 43-76

62. Pandit E, Sahoo A, Panda RK, Mohanty DP, Pani DR, Anandan A, Pradhan SK (2016) Survey of rice cultivars and landraces of upland ecology for phosphorous uptake 1(pup1) QTL using linked and gene specific molecular markers. Oryza 53(1):1-9

63. Pandit E, Tasleem S, Barik SR, Mohanty DP, Nayak DK, Mohanty SP, Das S, Pradhan SK (2017) Genome-wide association mapping reveals multiple QTLs governing tolerance response for seedling stage chilling stress in indica rice. Front Plant Sci 8:552. DOl:https://doi.org/10.3389/fpls.2017.00552

64. Pandit E, Panda RK, Sahoo A, Pani DR, Pradhan SK (2020) Genetic Relationship and Structure Analysis of Root Growth Angle for Improvement of Drought Avoidance in Early and Mid-Early Maturing Rice Genotypes. Rice Sci 27(2):124-132

65. Pradhan SK, Barik SR, Sahoo A, Mohapatra S, Nayak DK, Mahender A, Meher J, Anandan A, Pandit E (2016) Population structure, genetic diversity and molecular marker-trait association analysis for high temperature stress tolerance in rice. PLoS ONE 11 (8):123.DOI: https://doi. org/10.1371/ journal.pone. 0160027

66. Pradhan SK, Pandit E, Pawar S, Baksh SY, Mukherjee AK, Mohanty SP (2019a) Development of flash-flood tolerant and durable bacterial blight resistant versions of mega rice variety 'Swarna' through marker-assisted backcross breeding. Scientific reports 9:12810. https://doi.org/10.1038/s41598-01949176-z

67. Pradhan SK, Pandit E, Pawar S, Bharati B, Chatopadhyay K, Singh S, Dash Reddy P JN

68. b) Association mapping reveals multiple QTLs for grain protein content in rice useful for

69. biofortification.Mol Genet Genom 294(4):963-983. doi: 10.1007/s00438-019-01556-w

70. Pradhan SK, Pandit E, Pawar S, Naveenkumar R, Barik SR, Mohanty SP, Nayak DK

71. Ghritlahre SK, Rao DS, Reddy JN, Patnaik SSC (2020) Linkage disequilibrium mapping for

72. grain Fe and Zn enhancing QTLs useful for nutrient dense rice breeding. BMC Plant

73. Biol 20(1):57. DOI: 10.1186/s12870-020-2262-4

74. Pritchard JK, Stephens M, Donnelly P (2000) Inference of population structure using multilocus genotype data. Genetics 155:945-959

75. Rajjou L, Duval M, Gallardo K, Catusse J, Bally J, Job C, Job D.2012. Seed germination and

76. vigour. Annual Review Plant Biology 63: 507-533

77. Rao AN, Johnson DE, Sivaprasad B, Ladha JK, Mortimer AM (2007) Weed management in direct-seeded rice. AdvAgron 93:153-255

78. Redford PJ (1967) Growth analysis formulae their use and abuse.Crop Science7: 171-175

79. Redona ED, Mackill DJ (1996) Molecular mapping of quantitative trait loci in japonica rice

80. Genome39: 395-403.doi:10.1139/g96-050

81. Regan KL, Siddique KHM, Turner NC, Whan BR (1992) Potential for increasing early vigour and total biomass in spring wheat. II. Characteristics associated with early vigour. Australian J of AgrilResearch 43:541-553. doi:10.1071/ar9920541

82. Sahoo S, Sanghamitra P, Nanda N, Pawar S, Pandit E, Bastia R, Muduli KC, Pradhan SK (2020) Association of molecular markers with physio-biochemical traits related to seed vigour in rice. Physiology and Molecular Biology of Plants 26:1989-2003

83. Shukla V, Singh S, Singh H, Pradhan SK (2006) Multivariate analysis in tropical japonica" New plant type" rice (Oryza sativa L.). Oryza 43(3):203

84. Singh N, Choudhury DR, Singh AK, Kumar S, Srinivasan K, Tyagi R, Singh NK, Singh R (2013) Comparison of SSR and SNP Markers in Estimation of Genetic Diversity and Population Structure of Indian Rice Varieties. PLOS ONE 8(12):e84136. https://doi.org/10.1371/journal.pone.0084136

85. Singh RK, Chaudhary BD (1985) Biometrical Methods in Quantitative Analysis.Kalyani

Page $10 / 26$ 
86. Publishers, New Delhi

87. TASSEL: software for association mapping of complex traits in diverse samples. Bioinformatics 23: 2633-2635. doi: 10.1093/bioinformatics/btm308

88. To HTM, Nguyen HT, Dang NTM, Dang NTM, Nguyen NH, Bui TX, Lavarenne J, Phung NTP, GantetP,Lebrun M, Bellafiore S, Champion A (2019) Unraveling the Genetic Elements Involved in Shoot and Root Growth Regulation by Jasmonate in Rice Using a Genome-Wide Association Study. Rice 12:69. https://doi.org/10.1186/s12284-019-0327-5

89. Wang Z, Wan J, Bao Y, Wang F, Zhang H (2010) Quantitative trait loci analysis for rice seed vigor during the germination stage.J Zhejiang Univ-Sci B (Biomed and Biotechnol). 11(12): 958-964

90. Xie L, Tan Z, Zhou Y, Xu R, Feng L, Xing Y, Qi X (2014) Identification and fine mapping of quantitative trait loci for seed vigor in germination and seedling establishment in rice. J Integr Plant Biol 56:749-759

91. Yamauchi M, Winn T (1996) rice seed vigor and seedling establishment in anaerobic soil. Crop Sci 36:680-686

92. Yang J, Chang Y, Qin Y, Chen D, Zhu T, Peng K, Wang H, Tang N, Li X, Wang Y, Liu Y, Li X, Xie W, Xiong L (2020) A lamin-like protein OsNMCP1 regulates drought resistance and root growth through chromatin accessibility modulation by interacting with a chromatin remodeller OsSWI3C in rice. New Phytol 227:65-83. https://doi.org/10.1111/nph.16518

93. Yu J, Pressoir G, Briggs WH, Vroh Bi I, Yamasaki M, Doebley JF, Mc Mullen MD, Gaut

94. Nielsen BS, Holland DM, Kresovich JB, Buckler S (2006) A unified mixed model method for association mapping that accounts for multiple levels of relatedness. Nat Genet 38:203-208. doi:10.1038/ng1702 ES )

95. Zhang P, Li J, Li X, Liu X, Zhao X, Lu Y (2011) Population Structure and Genetic Diversity in a Rice Core Collection (Oryza sativa L.) Investigated with SSR Markers. PLOS ONE 6(12):e27565. https://doi.org/10.1371/journal.pone.0027565

96. Zhang P, Zhong K, Shahid MQ, Tong H (2017) Association analysis in rice: from application to utilization. Front in Plant Sci 7:1202. DOI:https://doi.org/10.3389/fpls.2016.01202

97. Zhang ZH, Qu XS, Wan S, Chen LH, Zhu YG (2005) Comparison of QTL controlling seedling vigor under different temperature conditions using recombinant inbred lines in rice (. Oryzasativa)Ann Bot 95(3):423-429

98. Zhao GW, Cao DD, Chen HY, Ruan GH, Yang MJ (2013) Seed Science and Technology, Volume 41(2):257-269 https://doi.org/10.15258/sst.2013.41.2.08

99. Zhao Y, Jiang C, Rehman RMA, Zhang HL, Li J, Li ZC (2019) Genetic analysis of roots and shoots in rice seedling by association mapping. Genes Genom 41::95-105. https://doi.org/10.1007/s13258-018-0741-x

100. Zuo J, Liu J, Gao F, Yin G, Wang Z, Chen F, Li X, Xu J, Chen T, Li L, Li Y, XiaX, Cao H

101. and Liu Y (2018) Genome-Wide Linkage Mapping Reveals QTLs for Seed Vigor-Related

102. Traits Under Artificial Aging in Common Wheat (Triticumaestivum). Frontier in Plant Science 9:1-11.doi:10.3389/fpls.2018.01101

\section{Tables}

Table 1 Mean values of 15 physiological traits estimated from the panel population containing 96 rice germplasm lines 


\begin{tabular}{|c|c|c|c|c|c|c|c|c|c|c|c|c|c|c|}
\hline SI.No. & $\begin{array}{l}\text { VarieAccession } \\
\text { No./Name of the } \\
\text { germplasm line }\end{array}$ & E.C. & RI & GI & G & RL & SL & SDW & SVII & SVI-II & RRG & RSG & RPE & RGR \\
\hline 1 & MNP-AC9005 & 62.35 & 0.0079 & 4.333 & 48.33 & 9.47 & 8.45 & 0.0120 & 849.97 & 0.563 & 0.803 & 1.109 & 0.29 & 0.077 \\
\hline 2 & MNP-AC9006 & 64.95 & 0.0084 & 3.917 & 45.00 & 7.36 & 8.612 & 0.0130 & 717.36 & 0.583 & 0.736 & 1.227 & 0.16 & 0.120 \\
\hline 3 & MNP-AC9021 & 32.45 & 0.0063 & 5.025 & 58.33 & 7.04 & 7.812 & 0.0080 & 865.33 & 0.477 & 0.240 & 1.099 & 0.23 & 0.146 \\
\hline 4 & MNP-AC9028 & 70.65 & 0.0077 & 2.808 & 30.00 & 6.85 & 8.44 & 0.0210 & 459.00 & 0.637 & 0.923 & 1.373 & 0.06 & 0.114 \\
\hline 5 & MNP-AC9030 & 78.85 & 0.0075 & 2.892 & 35.00 & 5.53 & 9.29 & 0.0255 & 514.27 & 0.898 & 0.527 & 1.767 & 0.10 & 0.239 \\
\hline 6 & MNP-AC9035 & 48.65 & 0.0067 & 2.200 & 25.00 & 5.77 & 9.93 & 0.0205 & 397.80 & 0.515 & 0.917 & 1.800 & 0.14 & 0.113 \\
\hline 7 & MNP-AC9038 & 44.6 & 0.0086 & 4.433 & 53.33 & 7.87 & 9.01 & 0.0190 & 891.87 & 1.020 & 0.903 & 1.623 & 0.20 & 0.276 \\
\hline 8 & MNP-AC9043 & 27.95 & 0.0092 & 4.708 & 50.00 & 6.78 & 9.28 & 0.0225 & 799.87 & 1.123 & 0.280 & 1.363 & 0.13 & 0.221 \\
\hline 9 & MNP-AC9044A & 40.95 & 0.0063 & 3.875 & 40.00 & 8.18 & 9.07 & 0.0185 & 690.00 & 0.740 & 1.247 & 1.103 & 0.09 & 0.272 \\
\hline 10 & MNP-AC9050 & 34.2 & 0.0067 & 1.800 & 34.00 & 4.62 & 3.1 & 0.0170 & 261.08 & 0.564 & 0.217 & 0.257 & 0.25 & 0.151 \\
\hline 11 & MNP-AC9053A & 38.7 & 0.0052 & 0.783 & 16.00 & 3.7 & 2.88 & 0.0050 & 105.28 & 0.080 & 0.140 & 0.857 & 0.27 & 0.013 \\
\hline 12 & MNP-AC9058 & 45.9 & 0.0062 & 2.092 & 38.00 & 5.29 & 3.49 & 0.0250 & 332.96 & 0.962 & 0.237 & 1.170 & 0.39 & 0.115 \\
\hline 13 & MNP-AC9063 & 71.4 & 0.0050 & 1.833 & 34.00 & 6.2 & 3.45 & 0.0250 & 326.12 & 0.856 & 0.367 & 1.190 & 0.11 & 0.126 \\
\hline 14 & MNP-AC9065 & 52.7 & 0.0066 & 2.725 & 46.00 & 6.52 & 4.32 & 0.0240 & 498.24 & 1.094 & 0.270 & 0.883 & 0.38 & 0.121 \\
\hline 15 & MNP-AC9076A & 52.4 & 0.0075 & 0.617 & 12.00 & 9.07 & 5.41 & 0.0150 & 173.76 & 0.180 & 0.543 & 0.133 & 0.58 & 0.195 \\
\hline 16 & MNP-AC9090 & 42.4 & 0.0064 & 2.167 & 38.00 & 8.18 & 3.67 & 0.0275 & 451.36 & 1.050 & 0.477 & 0.797 & 0.42 & 0.147 \\
\hline 17 & MNP-AC9093 & 34 & 0.0062 & 2.617 & 44.00 & 6.19 & 3.95 & 0.0295 & 446.16 & 1.298 & 0.457 & 0.573 & 0.37 & 0.150 \\
\hline 18 & JBS-AC20246 & 58.8 & 0.0072 & 3.208 & 48.00 & 5.58 & 8.26 & 0.0095 & 660.96 & 0.452 & 0.403 & 0.893 & 0.58 & 0.123 \\
\hline 19 & JBS-AC20282 & 78.6 & 0.0097 & 4.508 & 70.00 & 7.07 & 9.41 & 0.0113 & 1149.28 & 0.789 & 0.883 & 1.150 & 0.42 & 0.094 \\
\hline 20 & JBS-AC20317 & 50.8 & 0.0059 & 5.017 & 68.00 & 3.78 & 4.59 & 0.0110 & 569.16 & 0.442 & 0.347 & 0.150 & 0.33 & 0.146 \\
\hline 21 & JBS-AC20328 & 73.3 & 0.0073 & 6.217 & 86.00 & 6.21 & 8.39 & 0.0135 & 1255.68 & 1.161 & 0.540 & 1.120 & 0.34 & 0.100 \\
\hline 22 & JBS-AC20362 & 56.95 & 0.0063 & 6.175 & 84.00 & 5.61 & 7.78 & 0.0105 & 1129.04 & 0.886 & 0.377 & 0.810 & 0.55 & 0.100 \\
\hline 23 & JBS-AC20371 & 50.75 & 0.0075 & 7.417 & 94.00 & 5.74 & 8.7 & 0.0140 & 1356.84 & 1.318 & 0.347 & 1.193 & 0.19 & 0.100 \\
\hline 24 & JBS-AC20389 & 61.05 & 0.0062 & 5.708 & 80.00 & 5.57 & 6.94 & 0.0115 & 999.32 & 0.908 & 0.513 & 0.707 & 0.27 & 0.109 \\
\hline 25 & JBS-AC20423 & 50 & 0.0071 & 1.725 & 32.00 & 7.67 & 7.2 & 0.0100 & 475.64 & 0.204 & 1.090 & 0.590 & 0.205 & 0.142 \\
\hline 26 & JBS-AC20614 & 37.75 & 0.0060 & 2.475 & 40.00 & 4.56 & 4.73 & 0.0068 & 371.20 & 0.245 & 0.320 & 0.193 & 0.41 & 0.148 \\
\hline 27 & JBS-AC20664 & 52.9 & 0.0058 & 0.983 & 16.00 & 3.68 & 3.94 & 0.0045 & 121.84 & 0.078 & 0.220 & 0.290 & 0.43 & 0.080 \\
\hline 28 & JBS-AC20686 & 44.15 & 0.0041 & 1.050 & 16.00 & 4.91 & 5.78 & 0.0030 & 169.16 & 0.048 & 0.147 & 0.203 & 0.2 & 0.159 \\
\hline 29 & JBS-AC20627 & 41.45 & 0.0061 & 2.667 & 42.00 & 4.61 & 7.1 & 0.0050 & 492.52 & 0.212 & 0.227 & 0.700 & 0.37 & 0.013 \\
\hline 30 & JBS-AC20770 & 44.8 & 0.0065 & 3.592 & 56.00 & 5.91 & 9.13 & 0.0060 & 842.24 & 0.336 & 0.287 & 1.207 & 0.25 & 0.049 \\
\hline 31 & JBS-AC20845 & 82.25 & 0.0094 & 2.467 & 42.00 & 6.78 & 8.22 & 0.0107 & 629.84 & 0.453 & 0.510 & 1.030 & 0.14 & 0.101 \\
\hline 32 & JBS-AC20907 & 78.45 & 0.0067 & 1.733 & 30.00 & 4.71 & 5.67 & 0.0055 & 318.60 & 0.168 & 0.267 & 0.523 & 0.41 & 0.066 \\
\hline 33 & JBS-AC20920 & 55.6 & 0.0061 & 3.375 & 60.00 & 4.44 & 8.581 & 0.0085 & 771.67 & 0.504 & 1.133 & 0.940 & 0.26 & 0.039 \\
\hline 34 & JBS-AC20347 & 67.7 & 0.0076 & 1.633 & 28.00 & 4.04 & 7.09 & 0.0045 & 310.60 & 0.138 & 0.563 & 0.693 & 0.38 & 0.130 \\
\hline 35 & Kantakapura & 52.85 & 0.0063 & 4.033 & 70.00 & 5.23 & 7.43 & 0.0075 & 885.20 & 0.525 & 0.447 & 0.980 & 0.72 & 0.121 \\
\hline 36 & Kantakaamala & 52.75 & 0.0049 & 3.575 & 68.00 & 4.3 & 6.27 & 0.0062 & 713.20 & 0.419 & 0.640 & 0.370 & 0.67 & 0.082 \\
\hline 37 & kapanthi & 54.7 & 0.0054 & 4.317 & 76.00 & 10.02 & 7.74 & 0.0090 & 1349.76 & 0.684 & 0.677 & 1.513 & 0.54 & 0.066 \\
\hline 38 & Karpurkanti & 29.35 & 0.0037 & 3.717 & 70.00 & 4.25 & 5.21 & 0.0043 & 661.12 & 0.151 & 0.403 & 0.707 & 0.55 & 0.068 \\
\hline 39 & Kathidhan & 56.65 & 0.0077 & 1.983 & 38.00 & 7.03 & 6.74 & 0.0087 & 523.20 & 0.327 & 0.420 & 0.447 & 0.63 & 0.089 \\
\hline 40 & Kundadhan & 61.25 & 0.0068 & 0.867 & 20.00 & 4.93 & 5.72 & 0.0040 & 213.92 & 0.076 & 0.157 & 0.777 & 0.38 & 0.246 \\
\hline 41 & Champaeisiali & 50.8 & 0.0066 & 3.308 & 58.00 & 9.98 & 7.24 & 0.0082 & 1011.72 & 0.479 & 1.113 & 0.947 & 0.8 & 0.104 \\
\hline 42 & Latamahu & 67.5 & 0.0071 & 1.367 & 28.00 & 4.66 & 6.77 & 0.0065 & 318.48 & 0.182 & 0.830 & 0.323 & 0.81 & 0.221 \\
\hline
\end{tabular}




\begin{tabular}{|c|c|c|c|c|c|c|c|c|c|c|c|c|c|c|}
\hline 43 & Latachaunri & 61.4 & 0.0064 & 3.458 & 64.00 & 5.25 & 4.74 & 0.0048 & 633.20 & 0.303 & 0.417 & 0.237 & 0.5 & 0.197 \\
\hline 44 & Gondiachampeisiali & 39 & 0.0070 & 3.717 & 66.00 & 6.75 & 8.6 & 0.0098 & 1010.48 & 0.647 & 0.513 & 0.910 & 0.68 & 0.084 \\
\hline 45 & Chinamal & 47.4 & 0.0051 & 2.500 & 46.00 & 7.42 & 6.33 & 0.0088 & 637.40 & 0.411 & 0.583 & 0.533 & 0.41 & 0.199 \\
\hline 46 & Magra & 38.75 & 0.0053 & 1.617 & 30.00 & 7.68 & 5.38 & 0.0045 & 390.36 & 0.138 & 1.213 & 0.860 & 0.09 & 0.180 \\
\hline 47 & Landi & 38.2 & 0.0060 & 2.700 & 46.00 & 7.04 & 7.01 & 0.0040 & 672.60 & 0.184 & 0.747 & 0.843 & 0.65 & 0.030 \\
\hline 48 & Lalgundi & 63.45 & 0.0055 & 2.042 & 36.00 & 3.68 & 5.63 & 0.0060 & 334.88 & 0.054 & 0.243 & 0.600 & 0.68 & 0.143 \\
\hline 49 & $\begin{array}{l}\text { Balisaralaktimachi- } \\
\mathrm{k}\end{array}$ & 53.35 & 0.0070 & 2.325 & 40.00 & 7.58 & 7.23 & 0.0060 & 579.96 & 0.244 & 1.193 & 0.977 & 0.51 & 0.141 \\
\hline 50 & Laxmibilash & 22.7 & 0.0039 & 1.108 & 22.00 & 5.41 & 6.24 & 0.0045 & 257.00 & 0.096 & 0.273 & 0.377 & 0.6 & 0.259 \\
\hline 51 & Kaniar & 38.7 & 0.0067 & 3.800 & 66.00 & 5.46 & 8.42 & 0.0093 & 918.28 & 0.619 & 0.407 & 0.843 & 0.56 & 0.051 \\
\hline 52 & Kanakchampa & 35.5 & 0.0062 & 1.092 & 24.00 & 5.6 & 5.97 & 0.0085 & 277.68 & 0.204 & 0.733 & 0.457 & 0.33 & 0.308 \\
\hline 53 & Magura-s & 35.1 & 0.0054 & 1.575 & 32.00 & 5.46 & 7.17 & 0.0040 & 400.40 & 0.136 & 0.647 & 1.350 & 0.45 & 0.246 \\
\hline 54 & Adira-1Pallakad & 47.4 & 0.0061 & 1.617 & 28.00 & 6.56 & 7.15 & 0.0073 & 380.12 & 0.216 & 0.230 & 0.887 & 0.4 & 0.069 \\
\hline 55 & Adira-2PallakadR3 & 56.65 & 0.0049 & 5.083 & 84.00 & 7.9 & 7.42 & 0.0068 & 1273.20 & 0.592 & 0.753 & 0.890 & 0.43 & 0.065 \\
\hline 56 & Adira-3Pallakad & 40 & 0.0046 & 2.892 & 50.00 & 6.35 & 5.69 & 0.0058 & 602.68 & 0.293 & 0.533 & 0.840 & 0.21 & 0.109 \\
\hline 57 & PK6 & 44.7 & 0.0058 & 2.400 & 46.00 & 5.28 & 3.37 & 0.0048 & 400.24 & 0.178 & 0.463 & 0.620 & 0.15 & 0.157 \\
\hline 58 & PK14-Vachaw & 44.2 & 0.0060 & 4.192 & 74.00 & 4.05 & 2.98 & 0.0053 & 523.72 & 0.316 & 0.463 & 0.413 & 0.19 & 0.038 \\
\hline 59 & Pk-16Kozhivalan & 40.9 & 0.0055 & 3.767 & 66.00 & 4.47 & 4.2 & 0.0053 & 571.12 & 0.355 & 0.093 & 0.527 & 0.31 & 0.184 \\
\hline 60 & PK-17Marathondi & 50 & 0.0078 & 1.408 & 26.00 & 4.01 & 6.17 & 0.0043 & 264.20 & 0.112 & 0.360 & 1.067 & 0.37 & 0.057 \\
\hline 61 & PK-18Ezhoml-2 & 51.6 & 0.0071 & 4.192 & 74.00 & 3.51 & 3.5 & 0.0028 & 526.84 & 0.215 & 0.243 & 0.677 & 0.05 & 0.257 \\
\hline 62 & PK-19Cheruvirippu & 51.5 & 0.0070 & 3.242 & 56.00 & 3.63 & 3.71 & 0.0060 & 411.04 & 0.149 & 0.300 & 0.503 & 0.275 & 0.084 \\
\hline 63 & Pk-21 & 48.25 & 0.0056 & 5.842 & 100.00 & 5.53 & 5.98 & 0.0040 & 1151.00 & 0.400 & 0.787 & 1.613 & 0.27 & 0.059 \\
\hline 64 & $\begin{array}{l}\text { PK- } \\
\text { 22Gandhakasala }\end{array}$ & 36 & 0.0035 & 3.342 & 58.00 & 3.96 & 2.91 & 0.0028 & 397.76 & 0.152 & 0.720 & 0.670 & 0.14 & 0.091 \\
\hline 65 & PK-23Sreyas & 53.25 & 0.0051 & 1.792 & 32.00 & 3.92 & 3.42 & 0.0038 & 235.36 & 0.127 & 0.667 & 0.707 & 0.19 & 0.064 \\
\hline 66 & PK-24Jyothi & 43.55 & 0.0047 & 1.500 & 28.00 & 3.51 & 3.26 & 0.0040 & 190.40 & 0.112 & 0.423 & 0.737 & 0.19 & 0.251 \\
\hline 67 & PK-25Jaya & 41.4 & 0.0064 & 3.625 & 64.00 & 3.89 & 3.01 & 0.0047 & 442.00 & 0.300 & 0.527 & 0.507 & 0.24 & 0.273 \\
\hline 68 & PK-28Mahamaga & 42.7 & 0.0071 & 2.350 & 42.00 & 2.92 & 3.07 & 0.0015 & 250.08 & 0.066 & 0.443 & 0.617 & 0.19 & 0.100 \\
\hline 69 & PK-33D1 & 42.3 & 0.0054 & 1.725 & 34.00 & 2.72 & 2.67 & 0.0038 & 185.36 & 0.130 & 0.357 & 0.483 & 0.2 & 0.241 \\
\hline 70 & Jhagrikartik & 24.4 & 0.0048 & 1.233 & 20.00 & 6.54 & 3.37 & 0.0028 & 202.12 & 0.057 & 0.970 & 0.337 & 0.53 & 0.096 \\
\hline 71 & Dadghani & 39.35 & 0.0051 & 3.400 & 50.00 & 3.29 & 3.86 & 0.0028 & 357.40 & 0.137 & 0.110 & 0.340 & 0.15 & 0.096 \\
\hline 72 & Shayam & 36.75 & 0.0046 & 5.667 & 78.00 & 4.86 & 3.84 & 0.0016 & 676.52 & 0.127 & 0.810 & 0.473 & 0.24 & 0.070 \\
\hline 73 & Basumati-B & 26.05 & 0.0021 & 5.792 & 80.00 & 2.32 & 3.7 & 0.0026 & 481.60 & 0.100 & 0.290 & 0.663 & 0.29 & 0.066 \\
\hline 74 & Bharati & 51.4 & 0.0062 & 0.842 & 14.00 & 4.07 & 5.32 & 0.0050 & 131.64 & 0.070 & 0.127 & 0.747 & 0.19 & 0.183 \\
\hline 75 & Joha & 40.05 & 0.0051 & 1.050 & 20.00 & 2.47 & 2.7 & 0.0050 & 103.60 & 0.100 & 0.220 & 0.280 & 0.2 & 0.183 \\
\hline 76 & Jhingesal & 51.2 & 0.0042 & 2.142 & 34.00 & 5.77 & 5.12 & 0.0050 & 370.44 & 0.169 & 0.610 & 0.937 & 0.37 & 0.182 \\
\hline 77 & Sugandha-2 & 21.2 & 0.0028 & 6.000 & 84.00 & 3.75 & 2.69 & 0.0025 & 540.80 & 0.208 & 0.457 & 0.433 & 0.24 & 0.029 \\
\hline 78 & Gochi & 53.8 & 0.0048 & 1.667 & 26.00 & 2.71 & 3.9 & 0.0045 & 171.96 & 0.120 & 0.250 & 0.447 & 0.09 & 0.159 \\
\hline 79 & Uttarbangalocal-9 & 61.4 & 0.0056 & 0.617 & 10.00 & 3.38 & 2.31 & 0.0045 & 56.92 & 0.048 & 0.200 & 0.107 & 0.14 & 0.159 \\
\hline 80 & Chatuimuchi & 27.7 & 0.0046 & 5.900 & 84.00 & 3.89 & 3.36 & 0.0039 & 608.80 & 0.329 & 0.663 & 0.527 & 0.22 & 0.142 \\
\hline 81 & Palinadhan-1 & 32.8 & 0.0033 & 0.967 & 16.00 & 3.29 & 3.14 & 0.0024 & 102.88 & 0.038 & 0.267 & 0.660 & 0.28 & 0.075 \\
\hline 82 & AC-5993 & 57.5 & 0.0072 & 0.733 & 16.00 & 3.13 & 2.38 & 0.0155 & 88.16 & 0.248 & 0.260 & 0.317 & 0.35 & 0.347 \\
\hline 83 & AC-6007 & 38.45 & 0.0058 & 1.517 & 30.00 & 5.85 & 4.88 & 0.0070 & 323.28 & 0.093 & 0.973 & 0.880 & 0.21 & 0.034 \\
\hline 84 & AC-6023 & 48.4 & 0.0077 & 0.733 & 16.00 & 5.5 & 3.99 & 0.0100 & 151.84 & 0.160 & 1.070 & 0.947 & 0.38 & 0.126 \\
\hline 85 & AC- 6027 & 31.55 & 0.0054 & 0.833 & 18.00 & 3.94 & 3.93 & 0.0075 & 141.92 & 0.134 & 0.553 & 1.017 & 0.17 & 0.241 \\
\hline
\end{tabular}




\begin{tabular}{|llllllllllllllll}
86 & AC-6170 & 48.7 & 0.0053 & 4.300 & 84.00 & 3.42 & 2.92 & 0.0022 & 532.16 & 0.179 & 0.447 & 0.577 & 0.2 & 0.100 \\
\hline 87 & AC-6172 & 66.7 & 0.0065 & 4.367 & 80.00 & 4.31 & 4.25 & 0.0061 & 684.80 & 0.490 & 0.600 & 0.440 & 0.21 & 0.261 \\
\hline 88 & AC-6183 & 62.75 & 0.0048 & 1.942 & 36.00 & 8.85 & 3.69 & 0.0055 & 451.44 & 0.198 & 1.617 & 0.520 & 0.31 & 0.186 \\
\hline 89 & AC-6221 & 48.75 & 0.0050 & 3.742 & 70.00 & 3.9 & 2.99 & 0.0055 & 483.56 & 0.310 & 0.617 & 0.667 & 0.16 & 0.029 \\
\hline 90 & AC-7008 & 82.95 & 0.0071 & 0.733 & 16.00 & 4.18 & 3.93 & 0.0055 & 129.76 & 0.088 & 0.660 & 0.700 & 0.11 & 0.191 \\
\hline 91 & AC-7134 & 35.6 & 0.0058 & 0.917 & 20.00 & 3.87 & 3.27 & 0.0075 & 142.72 & 0.140 & 0.687 & 0.690 & 0.29 & 0.233 \\
\hline 92 & AC-7269 & 32.45 & 0.0037 & 0.833 & 18.00 & 3.32 & 2.96 & 0.0110 & 113.00 & 0.194 & 0.570 & 0.640 & 0.66 & 0.244 \\
\hline 93 & AC-7282 & 49.3 & 0.0072 & 0.917 & 20.00 & 4.21 & 4.11 & 0.0035 & 166.32 & 0.074 & 0.927 & 0.990 & 0.35 & 0.075 \\
\hline 94 & AC-10162 & 67.5 & 0.0070 & 1.283 & 28.00 & 5.12 & 4.03 & 0.0033 & 256.24 & 0.071 & 1.067 & 0.890 & 0.35 & 0.073 \\
\hline 95 & AC-10187 & 51.85 & 0.0059 & 4.292 & 80.00 & 8.15 & 5.1 & 0.0051 & 1060.2 & 0.412 & 1.917 & 0.667 & 0.22 & 0.157 \\
\hline 96 & AC-10608 & 39.4 & 0.0048 & 1.958 & 38.00 & 4.4 & 4.03 & 0.0046 & 320.51 & 0.175 & 0.440 & 0.850 & 0.12 & 0.121 \\
\hline LSD $5 \%$ & & 10.14 & 11.23 & 10.25 & 11.15 & 9.61 & 10.14 & 11.92 & 11.14 & 11.8 & 12.25 & 11.18 & 10.27 & 12.16 \\
\hline CV\% & & 11.15 & 0.0039 & 1.21 & 10.14 & 1.25 & 1.34 & 0.0058 & 1575 & 0.153 & 0.305 & 0.141 & 0.091 & 0.095 \\
\hline
\end{tabular}

E.C: E.C ( $\mu \mathrm{mhos} / \mathrm{cm} / 10$ seed); RI: Rate of imbibition; GI: Germination index; GP: Germination \%; RL: Root length (cm); SL: Shoot length (cm); SDW: Seedling dry weight (g); SVI-I: Seed Vigour index I; SVI-II: Seed Vigour index II; RRG: Rate of root growth; RSG: Rate of shoot growth; RPE: Rate of plumule elongation; RGR: Relative growth rate.

Table 2 Estimation of genetic diversity parameters based on 109 SSR marker loci in a panel containing 96 rice germplasm lines 


\begin{tabular}{|c|c|c|c|c|c|c|c|}
\hline SI. No & Marker & No. of Alleles & Major allele frquency & Gene diversity & Heterozygosity & PIC & $f$ \\
\hline 1 & RM5310 & 4 & 0.781 & 0.370 & 0.042 & 0.345 & 0.888 \\
\hline 2 & RM582 & 4 & 0.760 & 0.400 & 0.042 & 0.374 & 0.897 \\
\hline 3 & RM13335 & 4 & 0.536 & 0.525 & 0.010 & 0.417 & 0.980 \\
\hline 4 & RM6275 & 4 & 0.740 & 0.428 & 0.063 & 0.400 & 0.855 \\
\hline 5 & RM50 & 4 & 0.375 & 0.692 & 0.031 & 0.634 & 0.955 \\
\hline 6 & RM85 & 4 & 0.401 & 0.690 & 0.156 & 0.633 & 0.776 \\
\hline 7 & RM222 & 4 & 0.672 & 0.505 & 0.010 & 0.465 & 0.980 \\
\hline 8 & RM247 & 5 & 0.531 & 0.599 & 0.083 & 0.530 & 0.862 \\
\hline 9 & RM328 & 3 & 0.708 & 0.448 & 0.000 & 0.397 & 1.000 \\
\hline 10 & RM337 & 5 & 0.448 & 0.641 & 0.135 & 0.573 & 0.791 \\
\hline 11 & RM340 & 5 & 0.672 & 0.501 & 0.115 & 0.457 & 0.773 \\
\hline 12 & RM470 & 5 & 0.464 & 0.692 & 0.813 & 0.648 & -0.168 \\
\hline 13 & RM472 & 3 & 0.516 & 0.509 & 0.115 & 0.390 & 0.777 \\
\hline 14 & RM506 & 3 & 0.646 & 0.494 & 0.167 & 0.419 & 0.665 \\
\hline 15 & RM1812 & 3 & 0.479 & 0.604 & 0.000 & 0.521 & 1.000 \\
\hline 16 & RM3701 & 3 & 0.656 & 0.496 & 0.542 & 0.432 & -0.086 \\
\hline 17 & RM6947 & 3 & 0.875 & 0.225 & 0.000 & 0.210 & 1.000 \\
\hline 18 & RM14978 & 3 & 0.458 & 0.573 & 0.000 & 0.479 & 1.000 \\
\hline 19 & RM18776 & 3 & 0.828 & 0.293 & 0.031 & 0.265 & 0.895 \\
\hline 20 & RM22034 & 3 & 0.958 & 0.081 & 0.000 & 0.079 & 1.000 \\
\hline 21 & RM24161 & 4 & 0.625 & 0.530 & 0.146 & 0.467 & 0.727 \\
\hline 22 & RM223 & 5 & 0.651 & 0.534 & 0.073 & 0.498 & 0.865 \\
\hline 23 & RM440 & 5 & 0.417 & 0.655 & 0.292 & 0.589 & 0.558 \\
\hline 24 & RM201 & 3 & 0.568 & 0.559 & 0.031 & 0.480 & 0.945 \\
\hline 25 & RM216 & 4 & 0.547 & 0.593 & 0.156 & 0.527 & 0.739 \\
\hline 26 & RM258 & 3 & 0.417 & 0.654 & 0.000 & 0.580 & 1.000 \\
\hline 27 & RM286 & 4 & 0.448 & 0.655 & 0.115 & 0.589 & 0.827 \\
\hline 28 & RM3735 & 4 & 0.313 & 0.732 & 0.990 & 0.682 & -0.347 \\
\hline 29 & RM1347 & 3 & 0.542 & 0.531 & 0.000 & 0.428 & 1.000 \\
\hline 30 & RM7571 & 3 & 0.880 & 0.218 & 0.010 & 0.207 & 0.953 \\
\hline 31 & RM14723 & 4 & 0.552 & 0.597 & 0.250 & 0.533 & 0.585 \\
\hline 32 & RM103 & 3 & 0.500 & 0.520 & 0.958 & 0.405 & -0.842 \\
\hline 33 & RM315 & 2 & 0.917 & 0.153 & 0.000 & 0.141 & 1.000 \\
\hline 34 & RM225 & 3 & 0.552 & 0.504 & 0.229 & 0.387 & 0.549 \\
\hline 35 & RM486 & 3 & 0.771 & 0.362 & 0.063 & 0.310 & 0.829 \\
\hline 36 & RM256 & 3 & 0.849 & 0.262 & 0.073 & 0.237 & 0.724 \\
\hline 37 & RM1113 & 3 & 0.630 & 0.487 & 0.073 & 0.395 & 0.852 \\
\hline 38 & RM3423 & 3 & 0.500 & 0.588 & 0.000 & 0.504 & 1.000 \\
\hline 39 & RM6100 & 3 & 0.417 & 0.656 & 0.042 & 0.582 & 0.937 \\
\hline 40 & RM590 & 3 & 0.677 & 0.483 & 0.083 & 0.428 & 0.829 \\
\hline 41 & RM5739 & 3 & 0.667 & 0.500 & 0.021 & 0.449 & 0.959 \\
\hline 42 & RM405 & 3 & 0.833 & 0.291 & 0.000 & 0.270 & 1.000 \\
\hline 43 & RM547 & 5 & 0.474 & 0.568 & 0.177 & 0.474 & 0.691 \\
\hline
\end{tabular}




\begin{tabular}{|c|c|c|c|c|c|c|c|}
\hline 44 & RM7364 & 5 & 0.771 & 0.391 & 0.000 & 0.373 & 1.000 \\
\hline 45 & RM205 & 3 & 0.729 & 0.431 & 0.021 & 0.392 & 0.952 \\
\hline 46 & RM167 & 4 & 0.875 & 0.228 & 0.115 & 0.219 & 0.502 \\
\hline 47 & RM229 & 4 & 0.354 & 0.720 & 0.146 & 0.667 & 0.799 \\
\hline 48 & RM20A & 3 & 0.563 & 0.582 & 0.021 & 0.514 & 0.965 \\
\hline 49 & RM235 & 5 & 0.401 & 0.711 & 0.083 & 0.661 & 0.884 \\
\hline 50 & RM7003 & 4 & 0.760 & 0.388 & 0.104 & 0.348 & 0.734 \\
\hline 51 & RM4536 & 4 & 0.453 & 0.630 & 0.073 & 0.558 & 0.885 \\
\hline 52 & RM25181 & 5 & 0.474 & 0.681 & 0.208 & 0.633 & 0.697 \\
\hline 53 & RM469 & 3 & 0.578 & 0.558 & 0.052 & 0.484 & 0.908 \\
\hline 54 & RM6547 & 3 & 0.844 & 0.276 & 0.021 & 0.258 & 0.925 \\
\hline 55 & RM152 & 4 & 0.479 & 0.642 & 0.021 & 0.577 & 0.968 \\
\hline 56 & RM148 & 2 & 0.667 & 0.444 & 0.104 & 0.346 & 0.768 \\
\hline 57 & RM421 & 3 & 0.438 & 0.640 & 0.000 & 0.564 & 1.000 \\
\hline 58 & RM2634 & 3 & 0.417 & 0.653 & 0.021 & 0.579 & 0.968 \\
\hline 59 & RM248 & 4 & 0.333 & 0.737 & 0.073 & 0.688 & 0.902 \\
\hline 60 & RM7179 & 5 & 0.406 & 0.710 & 0.427 & 0.660 & 0.403 \\
\hline 61 & RM215 & 2 & 0.615 & 0.474 & 0.021 & 0.362 & 0.956 \\
\hline 62 & RM324 & 3 & 0.667 & 0.498 & 0.198 & 0.445 & 0.606 \\
\hline 63 & RM317 & 2 & 0.677 & 0.437 & 0.000 & 0.342 & 1.000 \\
\hline 64 & RM174 & 3 & 0.625 & 0.521 & 0.083 & 0.451 & 0.842 \\
\hline 65 & RM556 & 2 & 0.969 & 0.061 & 0.042 & 0.059 & 0.317 \\
\hline 66 & RM257 & 4 & 0.438 & 0.630 & 0.063 & 0.555 & 0.902 \\
\hline 67 & RM502 & 3 & 0.854 & 0.256 & 0.000 & 0.236 & 1.000 \\
\hline 68 & RM331 & 4 & 0.365 & 0.710 & 0.073 & 0.657 & 0.898 \\
\hline 69 & RM403 & 4 & 0.495 & 0.638 & 0.104 & 0.576 & 0.838 \\
\hline 70 & RM309 & 3 & 0.693 & 0.456 & 0.031 & 0.395 & 0.932 \\
\hline 71 & RM6641 & 3 & 0.583 & 0.573 & 0.000 & 0.510 & 1.000 \\
\hline 72 & RM3 & 3 & 0.385 & 0.662 & 0.010 & 0.588 & 0.984 \\
\hline 73 & RM594 & 3 & 0.557 & 0.561 & 0.010 & 0.480 & 0.982 \\
\hline 74 & RM3392 & 3 & 0.521 & 0.600 & 0.125 & 0.525 & 0.794 \\
\hline 75 & RM1278 & 3 & 0.771 & 0.378 & 0.083 & 0.344 & 0.781 \\
\hline 76 & RM168 & 3 & 0.625 & 0.490 & 0.188 & 0.397 & 0.621 \\
\hline 77 & RM3375 & 3 & 0.573 & 0.568 & 0.042 & 0.497 & 0.927 \\
\hline 78 & RM282 & 3 & 0.677 & 0.488 & 0.000 & 0.438 & 1.000 \\
\hline 79 & RM26632 & 4 & 0.375 & 0.701 & 0.198 & 0.646 & 0.720 \\
\hline 80 & RM1314 & 3 & 0.578 & 0.554 & 0.031 & 0.477 & 0.944 \\
\hline 81 & RM4112 & 3 & 0.568 & 0.583 & 0.198 & 0.518 & 0.664 \\
\hline 82 & RM20377 & 4 & 0.745 & 0.402 & 0.083 & 0.354 & 0.795 \\
\hline 83 & RM210 & 5 & 0.333 & 0.741 & 0.635 & 0.694 & 0.148 \\
\hline 84 & RM218 & 4 & 0.604 & 0.564 & 0.042 & 0.511 & 0.927 \\
\hline 85 & RM494 & 5 & 0.406 & 0.713 & 0.031 & 0.666 & 0.957 \\
\hline 86 & RM336 & 4 & 0.406 & 0.652 & 0.031 & 0.586 & 0.953 \\
\hline 87 & RM3475 & 4 & 0.479 & 0.604 & 0.052 & 0.524 & 0.915 \\
\hline
\end{tabular}

Page 16/26 


\begin{tabular}{|c|c|c|c|c|c|c|c|}
\hline 88 & RM480 & 4 & 0.630 & 0.539 & 0.031 & 0.487 & 0.943 \\
\hline 89 & RM566 & 4 & 0.438 & 0.648 & 0.021 & 0.580 & 0.968 \\
\hline 90 & RM11701 & 3 & 0.646 & 0.465 & 0.000 & 0.366 & 1.000 \\
\hline 91 & RM220 & 6 & 0.313 & 0.759 & 0.229 & 0.720 & 0.701 \\
\hline 92 & RM488 & 6 & 0.292 & 0.752 & 0.240 & 0.710 & 0.684 \\
\hline 93 & RM6374 & 6 & 0.307 & 0.770 & 0.094 & 0.733 & 0.879 \\
\hline 94 & RM233 & 5 & 0.365 & 0.713 & 0.292 & 0.660 & 0.594 \\
\hline 95 & RM112 & 3 & 0.854 & 0.254 & 0.000 & 0.231 & 1.000 \\
\hline 96 & RM13600 & 4 & 0.484 & 0.658 & 0.125 & 0.602 & 0.812 \\
\hline 97 & RM495 & 3 & 0.625 & 0.534 & 0.042 & 0.472 & 0.923 \\
\hline 98 & RM493 & 7 & 0.292 & 0.799 & 0.698 & 0.771 & 0.132 \\
\hline 99 & RM444 & 5 & 0.339 & 0.761 & 0.198 & 0.722 & 0.742 \\
\hline 100 & RM468 & 3 & 0.724 & 0.436 & 0.031 & 0.394 & 0.929 \\
\hline 101 & RM6054 & 3 & 0.917 & 0.156 & 0.021 & 0.150 & 0.868 \\
\hline 102 & RM509 & 3 & 0.813 & 0.314 & 0.000 & 0.281 & 1.000 \\
\hline 103 & RM5638 & 5 & 0.693 & 0.485 & 0.167 & 0.450 & 0.659 \\
\hline 104 & RM8044 & 6 & 0.349 & 0.764 & 0.281 & 0.728 & 0.635 \\
\hline 105 & RM8271 & 5 & 0.411 & 0.704 & 0.167 & 0.654 & 0.766 \\
\hline 106 & RM171 & 4 & 0.469 & 0.653 & 0.073 & 0.592 & 0.889 \\
\hline 107 & RM16686 & 3 & 0.396 & 0.655 & 0.000 & 0.581 & 1.000 \\
\hline 108 & RM434 & 4 & 0.479 & 0.650 & 0.031 & 0.587 & 0.952 \\
\hline \multirow[t]{2}{*}{109} & RM6091 & 4 & 0.823 & 0.311 & 0.000 & 0.294 & 1.000 \\
\hline & Mean & 3.706 & 0.578 & 0.533 & 0.117 & 0.477 & 0.783 \\
\hline
\end{tabular}

Table 3 The population structure group based on the inferred ancestry value of the germplasm lines present in the panel population for 15 physiological parameters 


\begin{tabular}{|c|c|c|c|c|c|c|c|c|c|}
\hline \multirow{2}{*}{$\begin{array}{l}\text { Sl. } \\
\text { No. }\end{array}$} & \multirow{2}{*}{$\begin{array}{l}\text { Accession No./ } \\
\text { Vernacular name of } \\
\text { germplasm line }\end{array}$} & \multicolumn{7}{|c|}{ Inferred ancestry value at $\mathrm{K}=6$} & \multirow{2}{*}{$\begin{array}{l}\text { physiological parameters with very high/high } \\
\text { estimates in the genotype }\end{array}$} \\
\hline & & Q1 & Q2 & Q3 & Q4 & Q5 & Q6 & Group & \\
\hline 1 & ARS-AC-5993 & 0.678 & 0.006 & 0.308 & 0.003 & 0.003 & 0.002 & Admix & EC, RI, GI, RL, SL, SVII, RRG, RSG, AGR, MGR \\
\hline 2 & ARS-AC-6221 & 0.989 & 0.002 & 0.003 & 0.002 & 0.002 & 0.001 & SP1 & EC, RI, GI, RL, SL, SVI-I, RRG, RSG, RGR, AGR, \\
\hline 3 & ARS-AC-6183 & 0.869 & 0.004 & 0.118 & 0.002 & 0.004 & 0.002 & SP1 & RI, GI, RL,SL, SVI-I, RSG, RGR, AGR, MGR \\
\hline 4 & ARS-AC-6170 & 0.539 & 0.003 & 0.443 & 0.004 & 0.008 & 0.001 & Admix & EC, RI, SL,SDW, RRG, RSG, RGR, AGR, MGR \\
\hline 5 & ARS-AC-6023 & 0.01 & 0.005 & 0.978 & 0.001 & 0.005 & 0.001 & SP3 & EC, RI, SL, SDW, SVI-II, RSG, RGR, AGR, MGR \\
\hline 6 & ARS-AC-6172 & 0.038 & 0.05 & 0.902 & 0.002 & 0.006 & 0.002 & SP3 & RI,SL,SDW, RRG, RSG,RGR, AGR,MGR \\
\hline 7 & ARS-AC- 6027 & 0.004 & 0.003 & 0.087 & 0.002 & 0.003 & 0.902 & SP6 & $\begin{array}{l}\text { RI,GI,RL,SL,SDW,SVI-I,SVI-II, RRG, RSG, RGR, } \\
\text { AGR,MGR }\end{array}$ \\
\hline 8 & ARS-AC-6007 & 0.024 & 0.004 & 0.957 & 0.008 & 0.005 & 0.002 & SP3 & RI,GI,SL,SDW,SVI-I,SVI-II, RSG, RGR, AGR,MGR \\
\hline 9 & MNP-AC-9006 & 0.066 & 0.009 & 0.729 & 0.023 & 0.166 & 0.007 & Admix & RI,GI,RL,SL,SDW,SVI-II, RRG, RSG, RGR, AGR,MGR \\
\hline 10 & MNP-AC-9021 & 0.005 & 0.021 & 0.961 & 0.004 & 0.009 & 0.002 & SP3 & RI,SDW, RGR \\
\hline 11 & MNP-AC-9028 & 0.003 & 0.005 & 0.943 & 0.005 & 0.041 & 0.003 & SP3 & Low for majority parameter \\
\hline 12 & MNP-AC-9030 & 0.042 & 0.008 & 0.929 & 0.002 & 0.018 & 0.001 & SP3 & RI,SDW,SVI-II, RSG, RGR, AGR,MGR \\
\hline 13 & MNP-AC-9035 & 0.059 & 0.016 & 0.671 & 0.033 & 0.205 & 0.014 & Admix & EC, SDW, SVI-II, RSG, RGR, AGR,MGR \\
\hline 14 & MNP-AC-9038 & 0.019 & 0.022 & 0.799 & 0.003 & 0.154 & 0.002 & SP3 & RI,SDW,SVI-II,RGR,AGR,MGR \\
\hline 15 & MNP-AC-9043 & 0.108 & 0.012 & 0.14 & 0.007 & 0.732 & 0.001 & Admix & RI,RL,SDW,RPE,RGR \\
\hline 16 & MNP-AC-9044A & 0.011 & 0.003 & 0.284 & 0.005 & 0.694 & 0.003 & Admix & RI,RL,SDW,SVI-II,RGR,AGR,MGR \\
\hline 17 & JBS-AC-20920 & 0.216 & 0.749 & 0.017 & 0.002 & 0.008 & 0.008 & Admix & RI,SDW,SVI-II,RGR,AGR,MGR \\
\hline 18 & JBS-AC-20907 & 0.652 & 0.242 & 0.013 & 0.003 & 0.089 & 0.001 & Admix & RI,GI,SL,RPE,RGR,AGR,MGR \\
\hline 19 & JBS-AC-20845 & 0.132 & 0.843 & 0.016 & 0.002 & 0.006 & 0.001 & SP2 & EC,RI,GI, G,RL,SL,SVI-I,SVI-II,RRG,RSG,AGR,MGR \\
\hline 20 & JBS-AC-20770 & 0.026 & 0.018 & 0.692 & 0.004 & 0.253 & 0.007 & Admix & GI,RGR,MGR \\
\hline 21 & JBS-AC-20627 & 0.004 & 0.043 & 0.004 & 0.003 & 0.945 & 0.001 & SP5 & EC,RI,GI,G,SL,SVIII,SVI-II,RSG,AGR,MGR \\
\hline 22 & JBS-AC-20686 & 0.302 & 0.034 & 0.004 & 0.002 & 0.656 & 0.002 & Admix & RI, GI, G,SL,SVI-I,SVI-II,RPE,AGR,MGR \\
\hline 23 & JBS-AC-20664 & 0.009 & 0.967 & 0.008 & 0.003 & 0.011 & 0.001 & SP2 & RI, GI, G,SL,SVI-I,SVI-II,RSG,AGR,MGR \\
\hline 24 & JBS-AC-20614 & 0.009 & 0.09 & 0.004 & 0.012 & 0.882 & 0.002 & SP5 & EC,RI,GI, G,SVI-I,SVI-II,RGR,AGR,MGR \\
\hline 25 & MP-Jhagrikartik & 0.643 & 0.177 & 0.01 & 0.001 & 0.166 & 0.002 & Admix & RI,RL,SL,RRG,RGR,AGR \\
\hline 26 & MP-Dadghani & 0.28 & 0.02 & 0.687 & 0.003 & 0.008 & 0.002 & Admix & Low for majority parameter \\
\hline 27 & MP-Shayam & 0.011 & 0.002 & 0.002 & 0.004 & 0.002 & 0.978 & SP6 & Low for majority parameter \\
\hline 28 & MP-Basumati-B & 0.01 & 0.003 & 0.006 & 0.301 & 0.006 & 0.673 & Admix & RGR \\
\hline 29 & MP-Bharati & 0.549 & 0.326 & 0.004 & 0.003 & 0.116 & 0.002 & Admix & RI,SL, \\
\hline 30 & MP-Joha & 0.819 & 0.143 & 0.007 & 0.009 & 0.021 & 0.002 & SP1 & RI,GI,SL,SVI-I,RSG,AGR \\
\hline 31 & KE-Adira-1-Pallakad & 0.026 & 0.005 & 0.064 & 0.885 & 0.015 & 0.005 & SP4 & EC,RI,SL,RSG,RGR,AGR \\
\hline 32 & KE-Adira-2-Pallakad-R3 & 0.816 & 0.048 & 0.076 & 0.004 & 0.054 & 0.001 & SP1 & $\mathrm{EC}, \mathrm{RI}$ \\
\hline 33 & KE-Adira-3-Pallakad & 0.024 & 0.016 & 0.015 & 0.915 & 0.023 & 0.006 & SP4 & RI,GI,SL,SVI-I,RRG,AGR \\
\hline 34 & KE-PK6 & 0.836 & 0.002 & 0.007 & 0.144 & 0.006 & 0.004 & SP1 & EC,RI,SL,RGR,AGR \\
\hline 35 & KE-PK14-Vachaw & 0.961 & 0.009 & 0.008 & 0.003 & 0.007 & 0.013 & SP1 & RI,GI,SL,SVI-I,RPE,RGR,AGR \\
\hline 36 & KE-PK16-Kozhivalan & 0.616 & 0.003 & 0.369 & 0.002 & 0.009 & 0.001 & Admix & GI, SVI-I,RPE,AGR \\
\hline 37 & KE-PK17-Marathondi & 0.002 & 0.006 & 0.002 & 0.98 & 0.002 & 0.009 & SP4 & GI,G,RL,SL, SVIII,RSG,RPE,AGR \\
\hline 38 & KE-PK18-Ezhoml-2 & 0.968 & 0.014 & 0.007 & 0.004 & 0.005 & 0.002 & SP1 & GI,G,RPE,AGR \\
\hline 39 & KE-PK24-Jyothi & 0.912 & 0.015 & 0.026 & 0.022 & 0.023 & 0.001 & SP1 & RI,RL,RPE \\
\hline 40 & OD-Kantakopura & 0.065 & 0.382 & 0.006 & 0.064 & 0.481 & 0.002 & Admix & $\mathrm{EC}, \mathrm{RI}, \mathrm{RGR}$ \\
\hline 41 & OD-Kantakaamala & 0.011 & 0.137 & 0.016 & 0.813 & 0.022 & 0.002 & SP4 & RI,GI,RL, SL, SVI-I,RRG,RPE,RGR,AGR \\
\hline
\end{tabular}




\begin{tabular}{|c|c|c|c|c|c|c|c|c|c|}
\hline 42 & OD-Kapanthi & 0.002 & 0.001 & 0.001 & 0.993 & 0.002 & 0.002 & SP4 & $\mathrm{EC}, \mathrm{RI}, \mathrm{RRG}, \mathrm{RPE}, \mathrm{RGR}, \mathrm{AGR}$ \\
\hline 43 & OD-Karpurkanti & 0.001 & 0.025 & 0.001 & 0.033 & 0.002 & 0.937 & SP6 & $\mathrm{EC}, \mathrm{RI}, \mathrm{GI}, \mathrm{RPE}, \mathrm{RGR}$ \\
\hline 44 & OD-Kathidhan & 0.369 & 0.541 & 0.028 & 0.004 & 0.046 & 0.012 & Admix & $\mathrm{RI}, \mathrm{GI}, \mathrm{SL}, \mathrm{SVI}-\mathrm{I}, \mathrm{RPE}, \mathrm{AGR}$ \\
\hline 45 & OD-Kundadhan & 0.011 & 0.973 & 0.006 & 0.004 & 0.005 & 0.001 & SP2 & $\mathrm{RL}, \mathrm{RGR}, \mathrm{AGR}$ \\
\hline 46 & OD-Champaeisiali & 0.017 & 0.942 & 0.008 & 0.011 & 0.021 & 0.002 & SP2 & RL, RRG, RGR, AGR \\
\hline 47 & OD-Latamahu & 0.038 & 0.928 & 0.01 & 0.012 & 0.009 & 0.002 & SP2 & $\mathrm{RL}, \mathrm{SL}, \mathrm{RRG}, \mathrm{RPE}, \mathrm{AGR}$ \\
\hline 48 & OD-Latachaunri & 0.04 & 0.94 & 0.005 & 0.006 & 0.008 & 0.002 & SP2 & $\mathrm{EC}, \mathrm{RPE}, \mathrm{RGR}$ \\
\hline 49 & ARS-AC-10608 & 0.984 & 0.005 & 0.004 & 0.002 & 0.005 & 0.001 & SP1 & $\mathrm{RI}, \mathrm{RL}, \mathrm{SL}, \mathrm{RRG}, \mathrm{RPE}, \mathrm{RGR}, \mathrm{AGR}$ \\
\hline 50 & ARS-AC-10187 & 0.57 & 0.006 & 0.117 & 0.002 & 0.304 & 0.002 & Admix & RPE,RGR \\
\hline 51 & ARS-AC-10162 & 0.648 & 0.006 & 0.243 & 0.025 & 0.03 & 0.048 & Admix & GI,SL, SVIII,RPE, AGR \\
\hline 52 & ARS-AC-7282 & 0.002 & 0.001 & 0.002 & 0.001 & 0.002 & 0.992 & SP6 & $\mathrm{RI}, \mathrm{RRG}, \mathrm{RGR}, \mathrm{AGR}$ \\
\hline 53 & ARS-AC-7269 & 0.01 & 0.003 & 0.979 & 0.002 & 0.006 & 0.001 & SP3 & SL,RSG, RGR,AGR \\
\hline 54 & ARS-AC-7134 & 0.01 & 0.013 & 0.739 & 0.016 & 0.015 & 0.208 & Admix & RI,SL, AGR \\
\hline 55 & ARS-AC-7008 & 0.184 & 0.07 & 0.157 & 0.002 & 0.586 & 0.001 & Admix & $\mathrm{GI}, \mathrm{G}, \mathrm{RL}, \mathrm{SL}, \mathrm{SVII}-\mathrm{I} R \mathrm{R}, \mathrm{AGR}$ \\
\hline 56 & MNP-AC-9093 & 0.023 & 0.009 & 0.782 & 0.002 & 0.18 & 0.004 & Admix & RGR,AGR \\
\hline 57 & MNP-AC-9090 & 0.007 & 0.009 & 0.796 & 0.014 & 0.153 & 0.021 & Admix & RGR,AGR \\
\hline 58 & MNP-AC-9076A & 0.008 & 0.407 & 0.553 & 0.003 & 0.027 & 0.001 & Admix & $\mathrm{GI}, \mathrm{G}$ \\
\hline 59 & MNP-AC-9065 & 0.008 & 0.009 & 0.401 & 0.069 & 0.5 & 0.012 & Admix & $\mathrm{GI}, \mathrm{RGR}$ \\
\hline 60 & MNP-AC-9063 & 0.115 & 0.595 & 0.128 & 0.017 & 0.144 & 0.001 & Admix & $\mathrm{RI}, \mathrm{RSG}, \mathrm{AGR}$ \\
\hline 61 & MNP-AC-9058 & 0.012 & 0.012 & 0.78 & 0.002 & 0.192 & 0.001 & Admix & $\mathrm{RI}, \mathrm{Gl}, \mathrm{G}, \mathrm{RGR}$ \\
\hline 62 & MNP-AC-9053A & 0.004 & 0.005 & 0.073 & 0.012 & 0.879 & 0.028 & SP5 & $\mathrm{RI}, \mathrm{Gl}$ \\
\hline 63 & MNP-AC-9050 & 0.017 & 0.024 & 0.016 & 0.027 & 0.913 & 0.003 & SP5 & GI,G, SVIII, RRG, RSG, AGR \\
\hline 64 & MNP-AC-9005 & 0.091 & 0.005 & 0.087 & 0.007 & 0.808 & 0.002 & SP5 & $\mathrm{Gl}, \mathrm{RRG}, \mathrm{AGR}$ \\
\hline 65 & JBS-AC-20389 & 0.017 & 0.006 & 0.6 & 0.23 & 0.146 & 0.002 & Admix & AGR \\
\hline 66 & JBS-AC-20371 & 0.065 & 0.01 & 0.088 & 0.002 & 0.833 & 0.002 & SP5 & RGR, AGR,MGR \\
\hline 67 & JBS-AC-20423 & 0.018 & 0.02 & 0.079 & 0.003 & 0.88 & 0.001 & SP5 & $\mathrm{RI}, \mathrm{Gl}, \mathrm{RGR}$, AGR \\
\hline 68 & JBS-AC-20362 & 0.084 & 0.014 & 0.018 & 0.006 & 0.873 & 0.006 & SP5 & $\mathrm{RI}, \mathrm{AGR}$ \\
\hline 69 & JBS-AC-20328 & 0.007 & 0.005 & 0.007 & 0.002 & 0.974 & 0.005 & SP5 & RGR \\
\hline 70 & JBS-AC-20317 & 0.008 & 0.01 & 0.004 & 0.002 & 0.972 & 0.004 & SP5 & RRG, RPE, AGR \\
\hline 71 & JBS-AC-20282 & 0.014 & 0.265 & 0.008 & 0.198 & 0.512 & 0.003 & Admix & GI \\
\hline 72 & JBS-AC-20246 & 0.019 & 0.006 & 0.005 & 0.165 & 0.787 & 0.018 & Admix & GI,G, RRG, AGR,MGR \\
\hline 73 & JBS-AC-20347 & 0.32 & 0.063 & 0.568 & 0.034 & 0.012 & 0.002 & Admix & $\mathrm{GI}, \mathrm{G}, \mathrm{MGR}$ \\
\hline 74 & MP-Palinadhan-1 & 0.002 & 0.003 & 0.058 & 0.81 & 0.018 & 0.107 & SP4 & $\mathrm{RI}, \mathrm{RGR}$ \\
\hline 75 & MP-Chatuimuchi & 0.001 & 0.001 & 0.001 & 0.005 & 0.001 & 0.99 & SP6 & RGR, MGR \\
\hline 76 & MP-Uttarbangalocal-9 & 0.12 & 0.124 & 0.528 & 0.212 & 0.015 & 0.001 & Admix & RGR, AGR \\
\hline 77 & MP-Gochi & 0.3 & 0.011 & 0.14 & 0.166 & 0.382 & 0.002 & Admix & $\mathrm{GI}, \mathrm{G}, \mathrm{MGR}$ \\
\hline 78 & MP-Sugandha-2 & 0.001 & 0.001 & 0.002 & 0.002 & 0.002 & 0.991 & SP6 & RGR \\
\hline 79 & MP-Jhingesal & 0.117 & 0.846 & 0.023 & 0.003 & 0.01 & 0.001 & SP2 & EC, RGR \\
\hline 80 & KE-PK-19-Cheruvirippu & 0.009 & 0.019 & 0.961 & 0.004 & 0.006 & 0.001 & SP3 & GI,G, RGR, AGR,MGR \\
\hline 81 & KE-PK-28-Mahamaga & 0.003 & 0.156 & 0.794 & 0.026 & 0.02 & 0.001 & SP3 & Low for majority parameter \\
\hline 82 & KE-PK-25-Jaya & 0.007 & 0.006 & 0.98 & 0.003 & 0.004 & 0.001 & SP3 & $\mathrm{RI}, \mathrm{SDW}, \mathrm{RGR}$ \\
\hline 83 & KE-PK-33-D1 & 0.02 & 0.003 & 0.766 & 0.204 & 0.004 & 0.003 & Admix & RRG, AGR \\
\hline 84 & KE-PK-21 & 0.011 & 0.187 & 0.774 & 0.02 & 0.007 & 0.001 & Admix & $\mathrm{RI}$, RRG, RGR, AGR \\
\hline 85 & KE-PK-22-Gandhakasala & 0.002 & 0.016 & 0.002 & 0.002 & 0.003 & 0.975 & SP6 & RSG, RGR, AGR \\
\hline
\end{tabular}




\begin{tabular}{|llllllllll|}
86 & KE-PK-23-Sreyas & 0.41 & 0.048 & 0.492 & 0.015 & 0.032 & 0.003 & Admix & GI, G, AGR,MGR \\
\hline 87 & OD-Gondiachampeisiali & 0.007 & 0.949 & 0.018 & 0.008 & 0.016 & 0.002 & SP2 & EC,RI,GI, G, RGR, AGR \\
\hline 88 & OD-Chinamal & 0.008 & 0.614 & 0.28 & 0.003 & 0.087 & 0.009 & Admix & EC, RL, RRG, RGR, AGR,MGR \\
\hline 89 & OD-Magra & 0.006 & 0.69 & 0.285 & 0.009 & 0.006 & 0.003 & Admix & GI, AGR \\
\hline 90 & OD-Landi & 0.005 & 0.982 & 0.006 & 0.002 & 0.004 & 0.001 & SP2 & EC,RI, RGR, AGR \\
\hline 91 & OD-Lalgundi & 0.002 & 0.982 & 0.004 & 0.003 & 0.006 & 0.004 & SP2 & RGR, AGR \\
\hline 92 & OD-Balisaralaktimachi-K & 0.002 & 0.984 & 0.003 & 0.003 & 0.006 & 0.002 & SP2 & RPE, RGR, AGR \\
\hline 93 & OD-Laxmibilash & 0.011 & 0.399 & 0.008 & 0.015 & 0.008 & 0.558 & Admix & RI, RRG, AGR \\
\hline 94 & OD-Kaniar & 0.006 & 0.973 & 0.011 & 0.002 & 0.004 & 0.004 & SP2 & EC,RI, RRG, AGR \\
\hline 95 & OD-Kanakchampa & 0.068 & 0.879 & 0.023 & 0.011 & 0.014 & 0.005 & SP2 & GI, G,RL, SVI-I, RRG, RGR, AGR,MGR \\
\hline 96 & OD-Magura-S & 0.003 & 0.957 & 0.003 & 0.005 & 0.007 & 0.025 & SP2 & RGR, AGR \\
\hline
\end{tabular}

Table 4 Analysis of molecular variance (AMOVA) of the sub-populations present in the panel population at K=6 for 15 physiological parameters in 96 rice germplasm lines

\begin{tabular}{|llllll|}
\hline Source & df & SS & MS & Est. Var. & $\%$ \\
\hline Among Pops & 6 & 820.641 & 136.774 & 3.616 & $12 \%$ \\
\hline Among Indiv & 89 & 4225.400 & 47.476 & 20.553 & $67 \%$ \\
\hline Within Indiv & 96 & 611.500 & 6.370 & 6.370 & $21 \%$ \\
\hline Total & 191 & 5657.542 & & 30.593 & $100 \%$ \\
F-Statistics & Value & P(rand >= data) & & \\
\hline Fst & 0.118 & 0.001 & & & \\
\hline Fis & 0.763 & 0.001 & & & \\
\hline Fit & 0.791 & 0.001 & & & \\
\hline Fst max & 0.509 & & & & \\
\hline F'st & 0.233 & & & & \\
Nm & 1.861 & & & & \\
\hline
\end{tabular}

Table 5 Marker alleles association with physiological parameters detected by both the models of GLM and MLM analyses at p<0.01 rice germplasm lines present in the panel. 


\begin{tabular}{|c|c|c|c|c|c|c|c|c|c|c|c|}
\hline SL.No & Traits & Marker & $\begin{array}{l}\text { Position } \\
\text { (cM) }\end{array}$ & \multicolumn{4}{|l|}{ GLM } & \multicolumn{4}{|l|}{ MLM } \\
\hline 1 & RI & RM248 & 155 & 8.98583 & 0.00353 & 0.07563 & 0.005814 & 7.17908 & 0.00879 & 0.07053 & 0.009116 \\
\hline 2 & $\mathrm{GI}$ & RM225 & 92 & 13.59483 & $3.90 \mathrm{E}-04$ & 0.12244 & 0.001041 & 12.50148 & $6.48 \mathrm{E}-04$ & 0.12881 & 0.004536 \\
\hline 3 & GI & RM229 & 125 & 7.37835 & 0.00793 & 0.07074 & 0.008369 & 7.28108 & 0.00834 & 0.07502 & 0.009116 \\
\hline 5 & GI & RM502 & 177 & 29.01418 & 5.81E-07 & 0.22718 & $1.63 \mathrm{E}-05$ & 16.95205 & $8.56 \mathrm{E}-05$ & 0.17467 & 0.001198 \\
\hline 6 & $\mathrm{GI}$ & RM5638 & 284 & 14.91459 & $2.13 \mathrm{E}-04$ & 0.13263 & 0.001041 & 8.7923 & 0.00388 & 0.09059 & 0.00776 \\
\hline 7 & GP & RM225 & 92 & 13.74601 & $3.63 \mathrm{E}-04$ & 0.12756 & 0.001041 & 10.84335 & 0.00142 & 0.11297 & 0.005507 \\
\hline 8 & GP & RM502 & 177 & 18.43784 & $4.46 \mathrm{E}-05$ & 0.16363 & 0.000416 & 10.41549 & 0.00175 & 0.10851 & 0.005507 \\
\hline 12 & SVI-2 & RM7003 & 132 & 7.34405 & 0.00807 & 0.05881 & 0.008369 & 9.70644 & 0.00247 & 0.10386 & 0.006644 \\
\hline 13 & SVI-2 & RM5638 & 284 & 7.98095 & 0.00583 & 0.06349 & 0.007773 & 8.84629 & 0.00378 & 0.09466 & 0.00776 \\
\hline 14 & RRG & RM256 & 97 & 13.93515 & 3.33E-04 & 0.12877 & 0.001041 & 8.11243 & 0.00546 & 0.08683 & 0.009116 \\
\hline 15 & RSG & RM3701 & 45 & 14.75164 & $2.29 \mathrm{E}-04$ & 0.14083 & 0.001041 & 7.96593 & 0.00588 & 0.08679 & 0.009116 \\
\hline 16 & RSG & RM7003 & 132 & 7.26461 & 0.00841 & 0.07475 & 0.00841 & 12.99803 & $5.14 \mathrm{E}-04$ & 0.14162 & 0.009116 \\
\hline 17 & RSG & RM6547 & 145 & 7.56795 & 0.0072 & 0.07763 & 0.008369 & 7.27751 & 0.00835 & 0.07929 & 0.004536 \\
\hline 18 & RPE & RM403 & 183 & 11.73481 & $9.30 \mathrm{E}-04$ & 0.08487 & 0.00186 & 7.46605 & 0.00758 & 0.06992 & 0.009116 \\
\hline 24 & MGR & RM502 & 177 & 8.07998 & 0.00555 & 0.06585 & 0.007773 & 10.92039 & 0.00137 & 0.11013 & 0.005507 \\
\hline 25 & MGR & RM220 & 240 & 12.40579 & 6.78E-04 & 0.09679 & 0.001582 & 10.73664 & 0.0015 & 0.10828 & 0.005507 \\
\hline
\end{tabular}

\section{Figures}

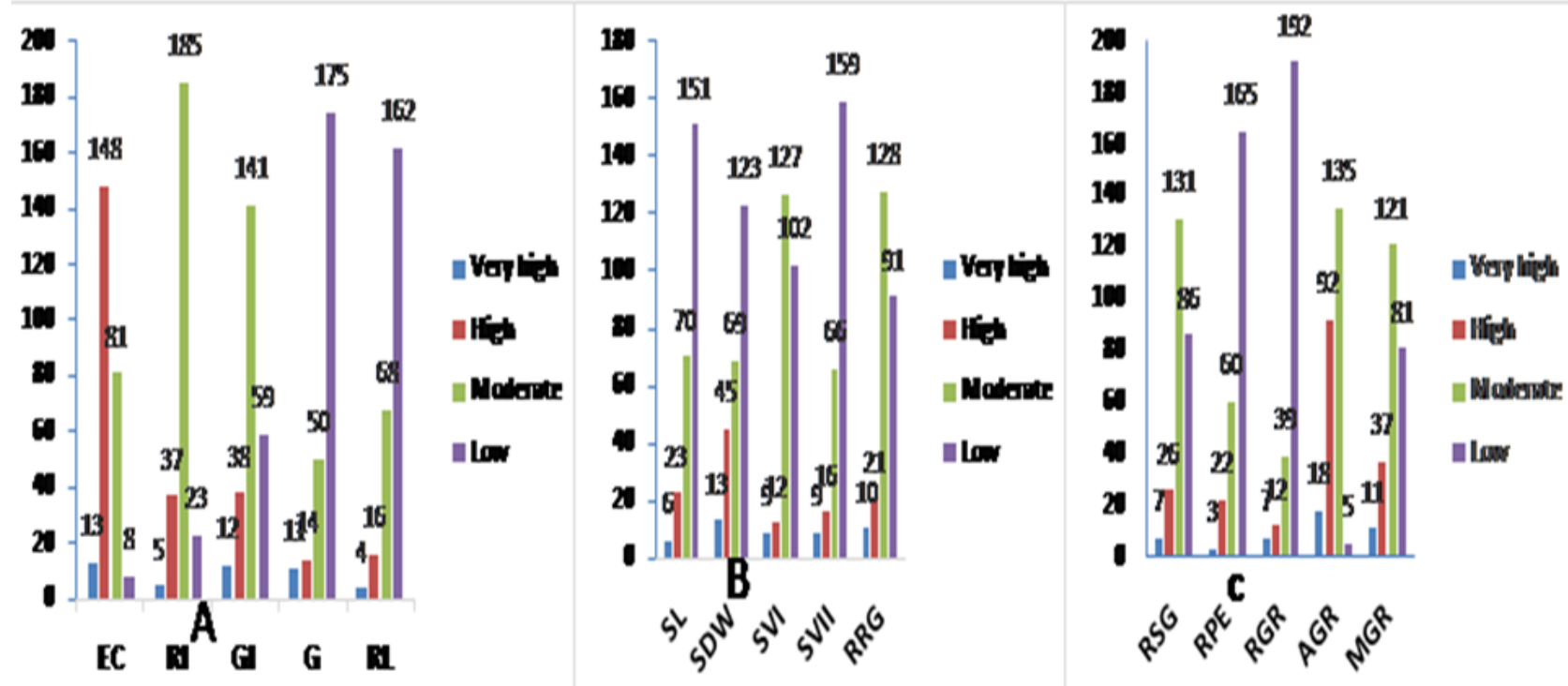




\section{Figure 1}

Frequency distribution of germplasm lines for each of the physiological parameters for (A) EC, RI, GI, GP and RL (B) SL, SDW, SVI-I, SVI-II and RRG, and (C) RSG, RPE, RGR, AGR and GR present in 250 germplasm lines.

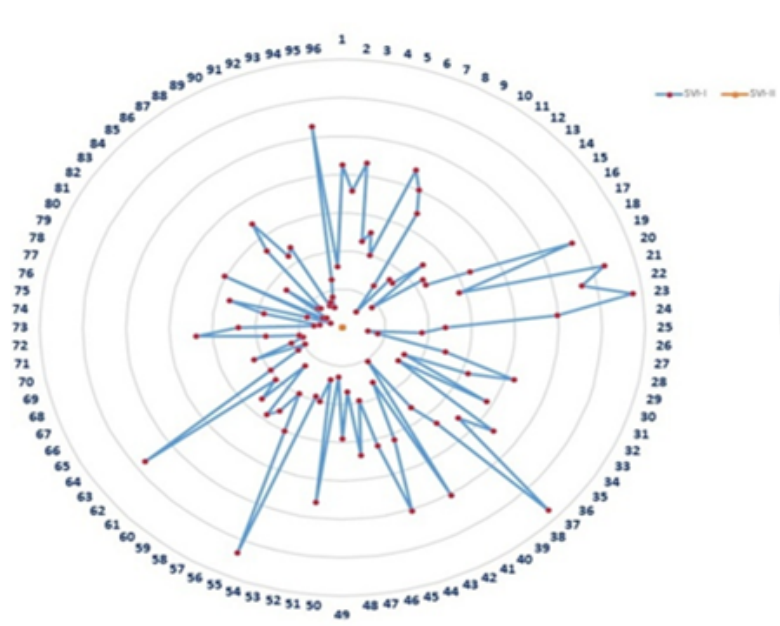

A

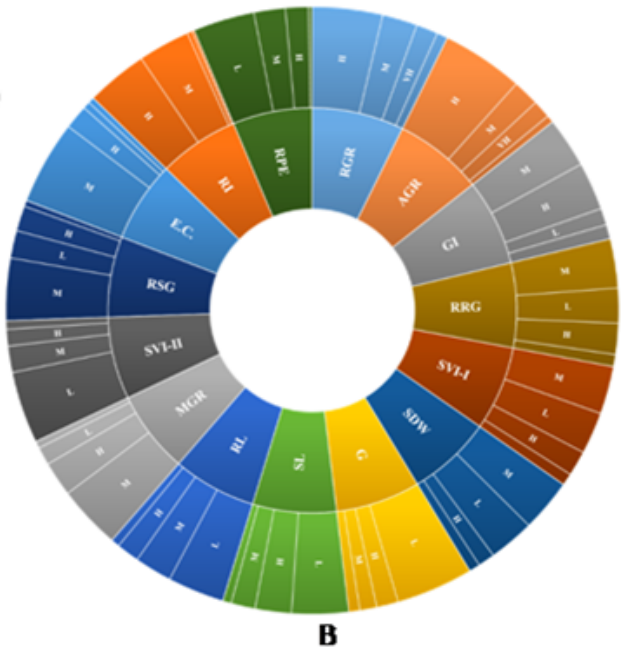

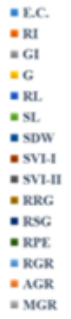

Figure 2

Frequency distribution of germplasm lines in the panel population for (A) Spider graph based on seed vigour index-I and (B) Based on 15 physiological parameters. VH: very high; $\mathrm{H}$ : high; $\mathrm{M}$ : medium; L: low. Classification of each trait into distinct group $(\mathrm{VH}, \mathrm{H}, \mathrm{M}$, and $\mathrm{L})$ is represented by proportion of colour.

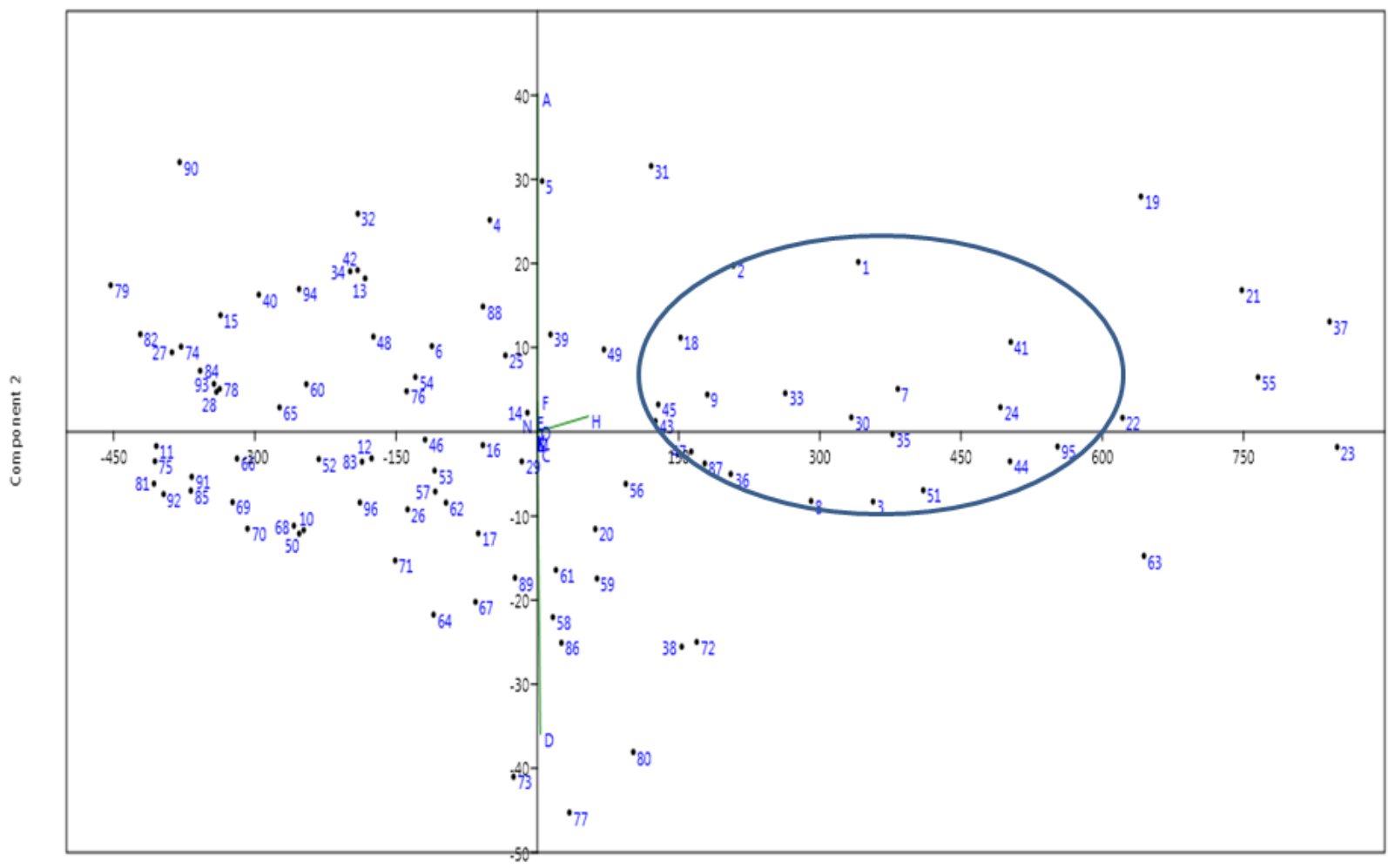

Component 1

Figure 3

Genotype-by-trait bi-plot diagram showing 96 germplasm lines in two PCs for 15 physiological traits. E.C: E.C ( $\mu \mathrm{mhos} / \mathrm{cm} / 10$ seed); RI: Rate of imbibition; GI: Germination index; G: Germination \%; RL: Root length (cm); SL: Shoot length (cm); SDW: Seedling dry weight (g); SVI-I: Seed vigour index l; SVI-II: Seed vigour index II; RRG: Rate of root growth; RSG: Rate of shoot growth; RPE: Rate of plumule elongation; RGR: Relative growth rate. The dot numbers in the diagram depict the serial number of the germplasm line listed in Table 1. 


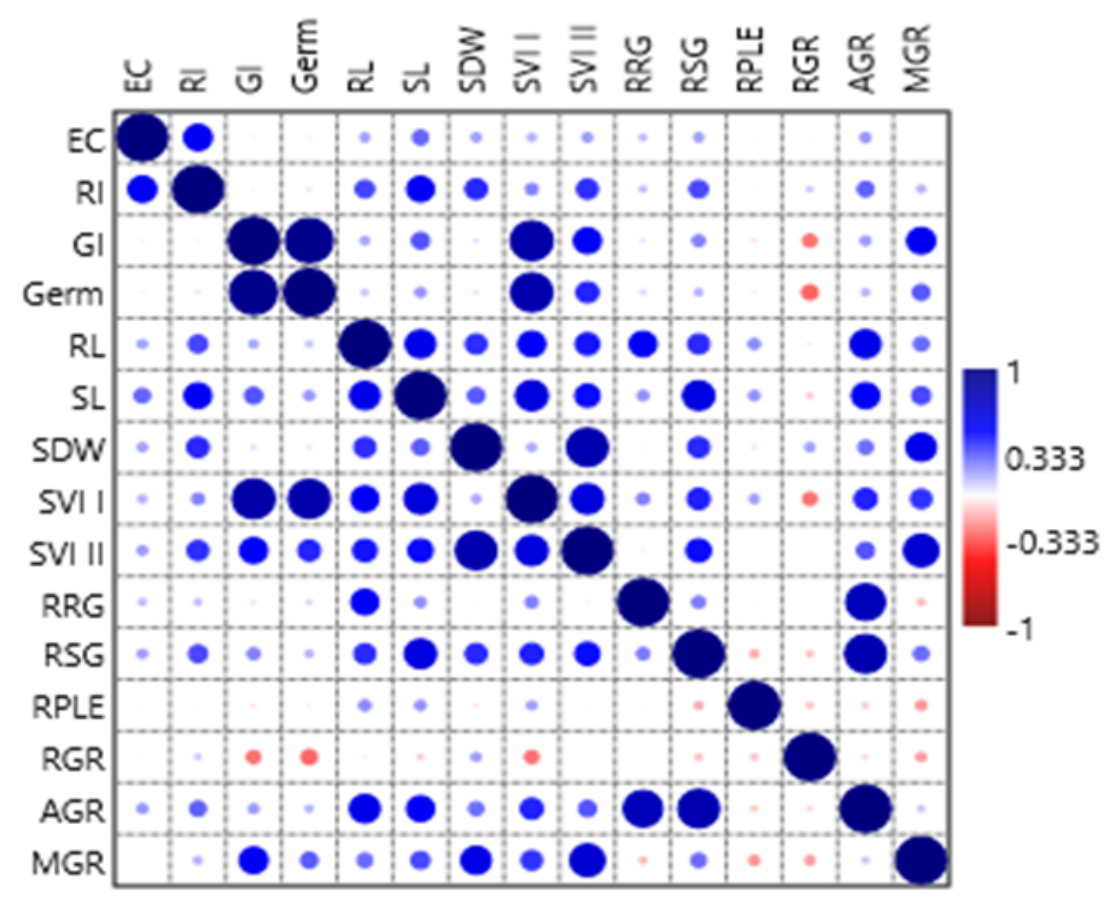

Figure 4

Heat map showing Pearson's correlation coefficients for physiological traits. Significant correlations are colored either in red (negative) or blue (positive). Shades of blue indicate increasing positive correlation coefficient; shades of red indicate increasing negative correlation coefficient. EC: electrical conductivity; RI: rate of imbibition; G: germination \%; RL: root length; SL: shoot length; SDW: seedling dry weight; SVI I: seed vigour index I; SVI II: seed vigour index II; RRG: rate of root growth; RSG: rate of shoot growth; RPE: rate of plumule elongation; RGR: rate of growth rate; AGR: absolute growth rate and GR: mean germination rate.
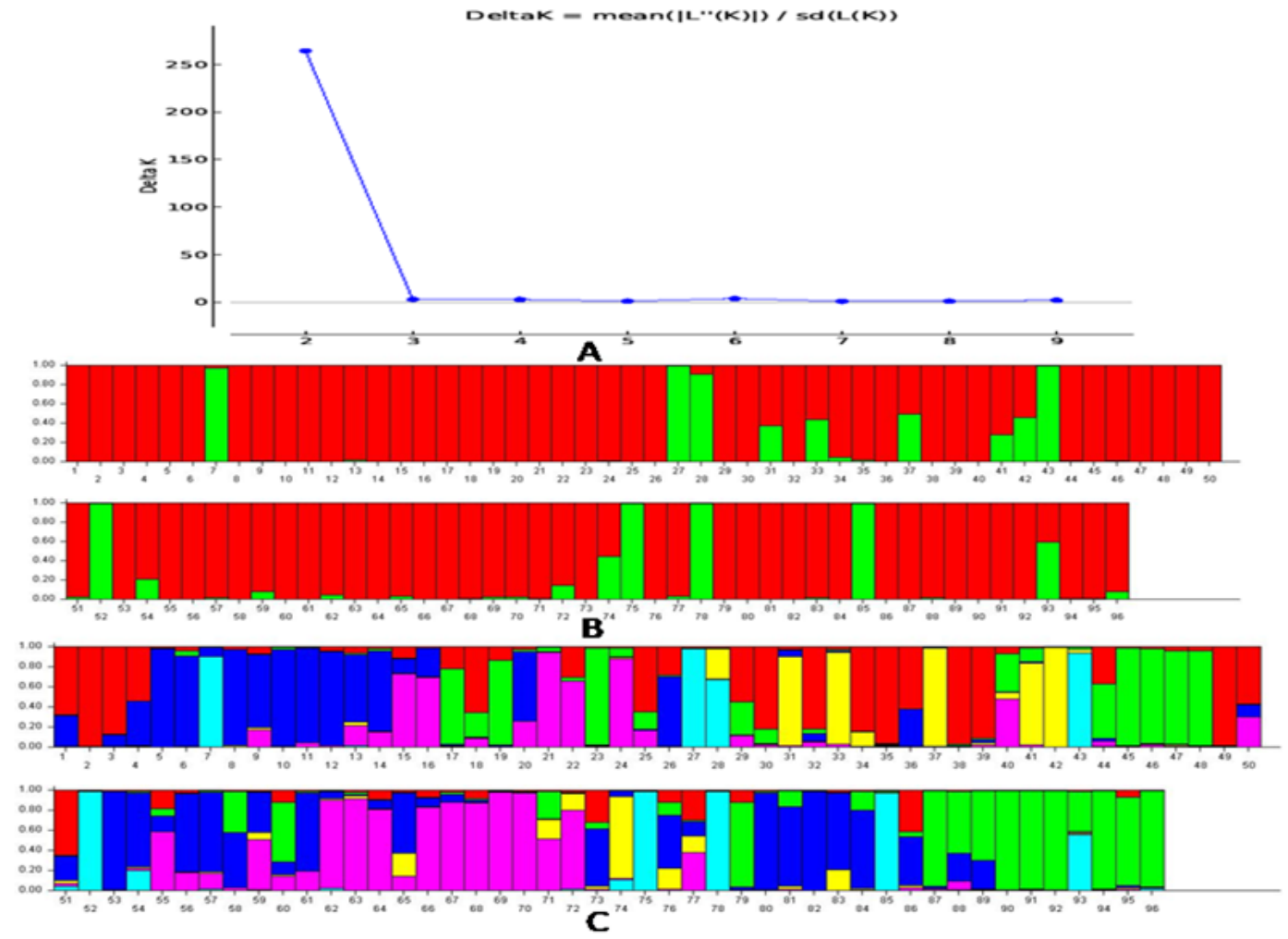

Figure 5 
A) Graph of $\Delta K$ value, to the rate of change in the log probability of data between successive $K$ values; B) Population structure of the 96-panel population placed based on membership probability fractions of individual genotypes at $\mathrm{K}=2$, c) Population structure of the panel population at $\mathrm{K}=6$. The genotypes with the probability of $\geq 80 \%$ membership proportions were assigned as subgroups while others grouped as admixture group. The numbers in the diagram depict the serial number of the germplasm lines listed in Table 1.

\section{LD Plot}

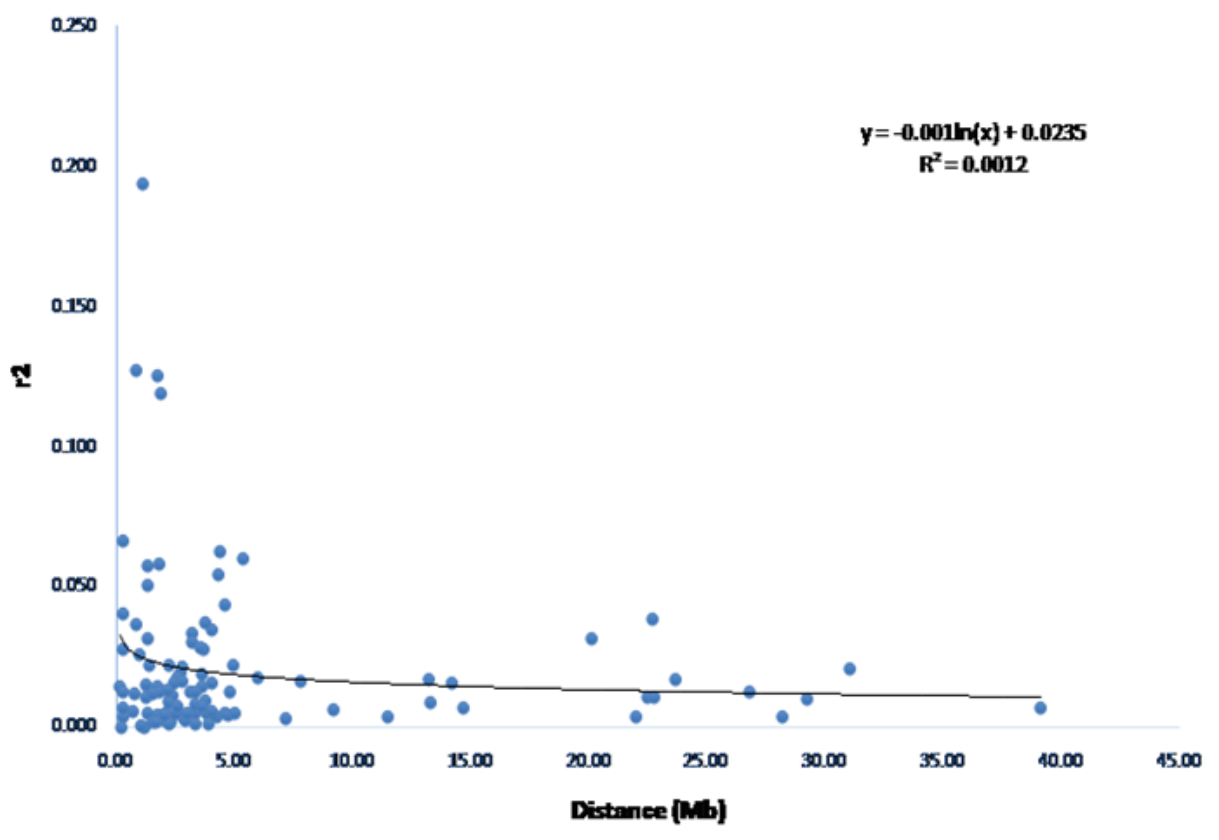

\section{Figure 6}

The physical distance (base pairs, bp) between pairs of loci on chromosomes against linkage disequilibrium (LD) decay ( $\mathrm{r} 2$ ) curve plotted in rice. The decay started in million bp estimated by taking 95th percentile of the distribution of $\mathrm{r} 2 \mathrm{for}$ all unlinked loci.

Factorial analysis: (Axes 1/2)

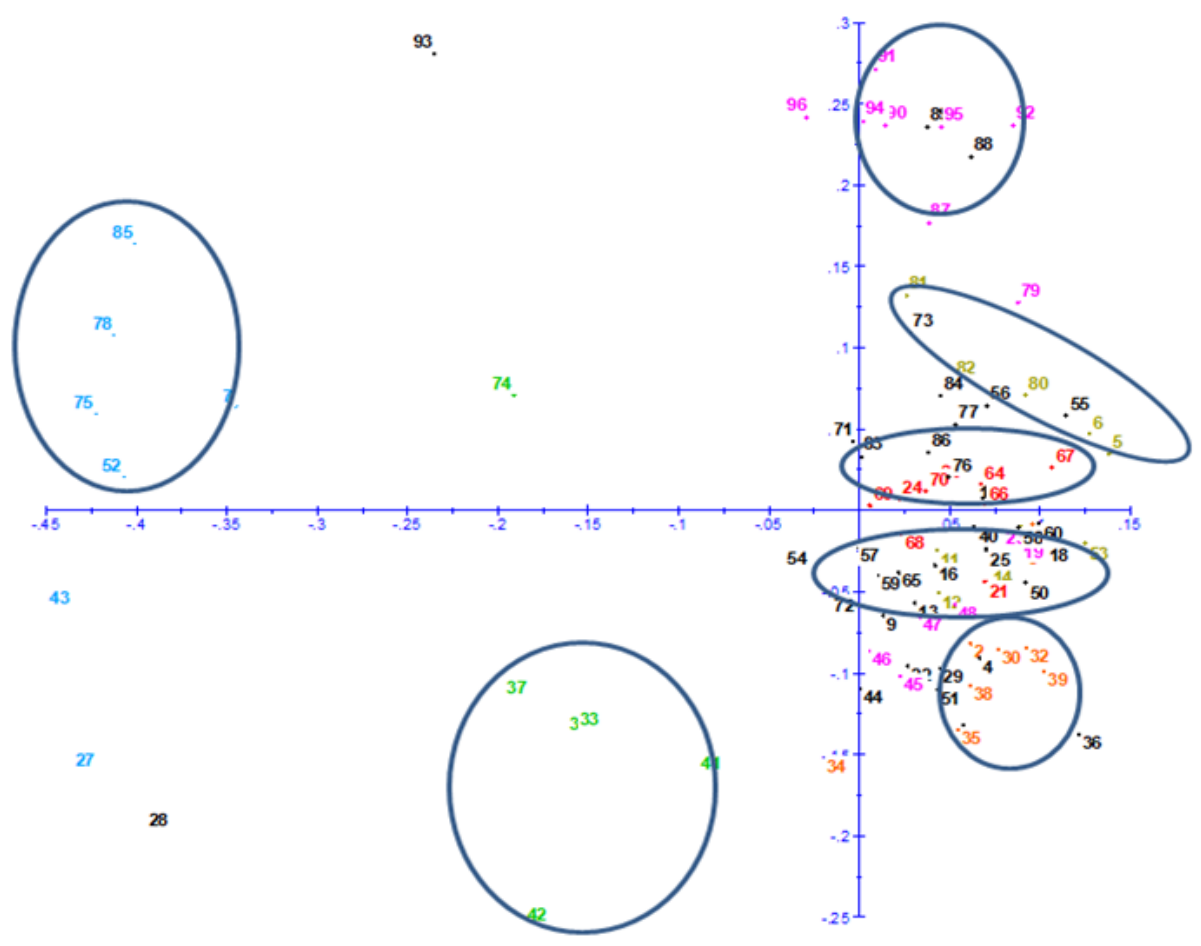

Figure 7 
Principal coordinate analysis (PCoA) of 96 genotypes in the panel population for 15 physiological traits using 109 molecular markers. The dot numbers in the figure represent the serial number of the genotypes enlisted in Table 1. The numbers are coloured on the basis of sub-populations obtained from structure analysis (SP1-Orange; SP2-Pink; SP3-Brown; SP4-Green; SP5-Red; SP6-Light Blue; admix type-Black).

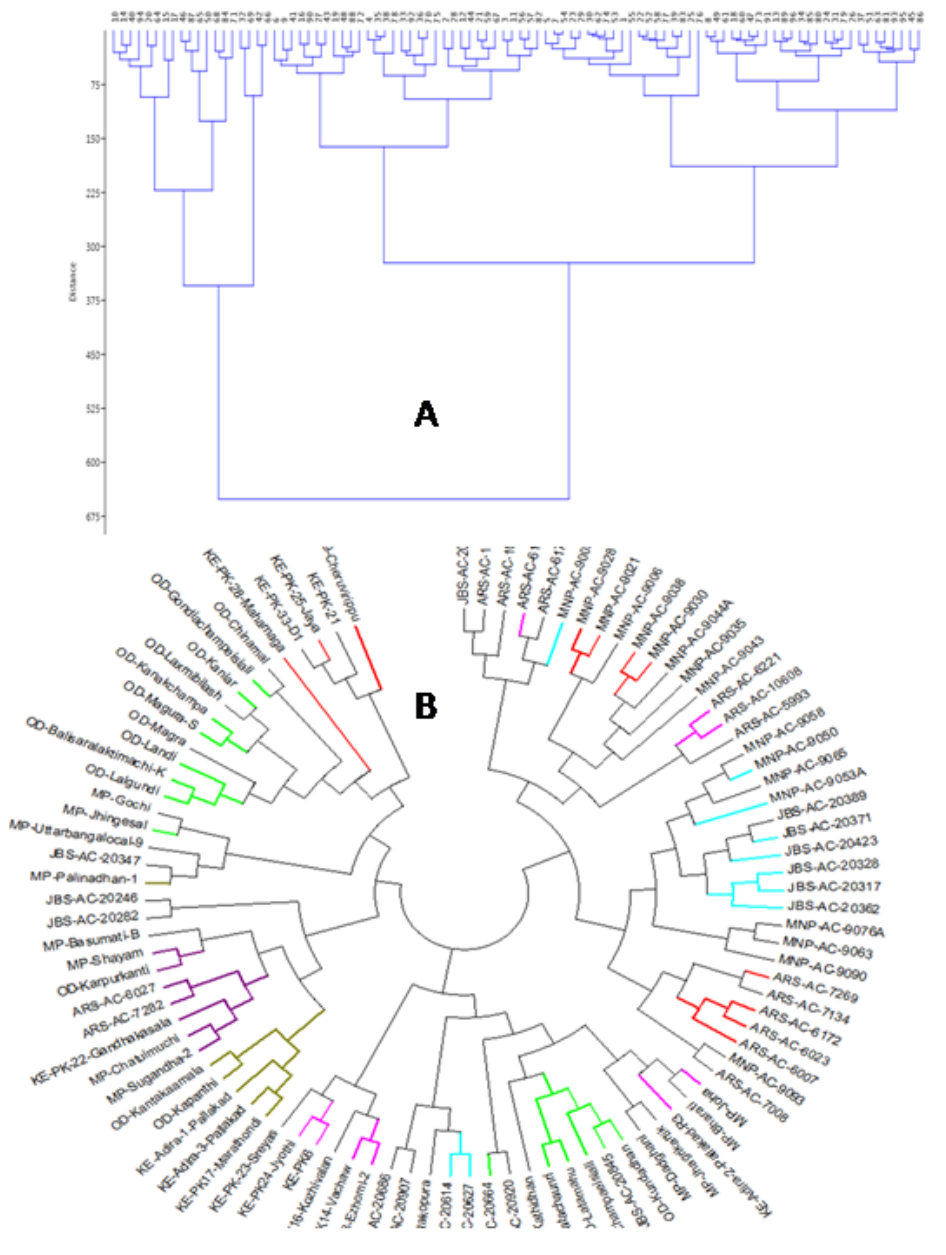

Figure 8

Unrooted tree using unweighted-neighbour joining method depicting clustering pattern of 96 germplasm lines genotyped by 109 SSR markers coloured on the basis of (A) Fifteen physiological parameters, (B) sub-populations obtained from structure analysis at K=6 (SP1-Pink; SP2-Green; SP3-Red; SP4-Brown; SP5Light Blue; SP6-Violet; admix type-Black).

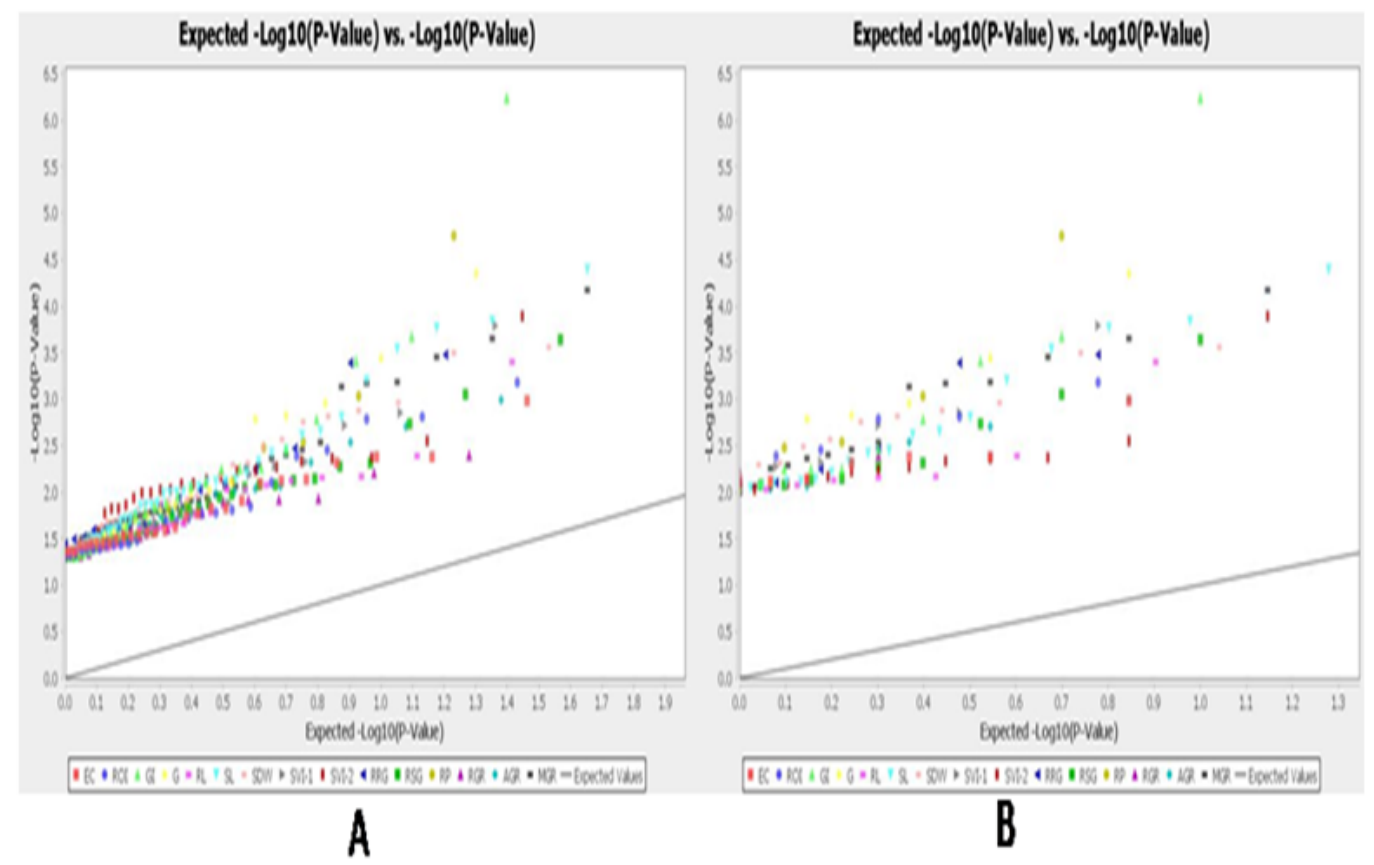

Page $25 / 26$ 
Figure 9

Distribution of marker-trait association and quantile-quantile (Q-Q) plot generated from Generalized Linear Model analysis for 15 physiological parameters at (A) $p<0.05$ and (B) at $p<0.01$.

\section{Supplementary Files}

This is a list of supplementary files associated with this preprint. Click to download.

- SupplementaryFig.1.tif

- SupplementaryFig.2.tif

- SupplementaryTable1.xlsx

- SupplementaryTable2.docx

- SupplementaryTable3.csv

- SupplementaryTable4.csv 